\title{
Geophysical Modelling of Typical Cavity Shapes to Calculate Detection Probability and Inform Survey Design
}

\author{
Paul James ${ }^{1}$ and Pedro Ferreira ${ }^{1}$ \\ ${ }^{1}$ Civil, Environmental and Geomatic Engineering, University College London, London, WC1E \\ 6BT \\ Email: paul.james.09@ucl.ac.uk
}

\begin{abstract}
Feasibility analysis of near surface cavity detection is presented using modelling of the gravity, gravity gradient, magnetic, magnetic gradient, and ground penetrating radar techniques. The geophysical signal is modelled over typical cavity shapes in three dimensional subsurface environments with varying geologies and survey parameters. The cavity detection probability is calculated for each technique in the outlined environments and these values are used aid technique choice, assess the feasibility of cavity detection, assess the limits of detection for each technique, and optimise survey design before entering the field.

Tests in a range of conditions show that technique choice is conditional to site characteristics and site parameters and highlight the need for modelling in the desk study stage of site investigation and survey design. Detection probability results show that standard survey direction practice in magnetometry is not always optimal and demonstrate the importance of site specific noise level consideration. Comparisons with case study measurements demonstrate that the process chose appropriate techniques and survey parameters but also highlights the limitations of the method.
\end{abstract}

\section{Introduction}

A growing need for housing has led the U.K. government to increase development of brownfield sites (Barclay, 2010). However, old mine workings and natural cavities represent potential hazards before, during and after construction on such sites, and complicate the subsurface investigation. Cavity collapse, mine breach and water contamination must all be considered. Natural and manmade cavities are a widespread feature across the U.K. (British Geological Survey, 2010; British Geological Society, 2011) but not all are recorded. The 1872 Coal Mines Regulation Act required all U.K. mines to be mapped but an estimated 30,000 of 100,000 mine workings are unmapped (Littlejohn, 1979). Map projection changes through time mean mapped mine locations are questionable or located more than once. In other countries, illegal, unlicensed and unmapped mining is still prevalent; it is estimated that 65,000 unlicensed mines in China were shut down between 2005 and 2008 (Ali, 2009). Over 12,000 natural cavities on chalk (and 3,500 chalk mines) are recorded in the U.K. but most natural cavities remain unrecorded (Edmonds, 2008). Cavities are hence a limitation to certain redevelopment and their detection and delineation is an ever important consideration in risk reduction and foundation design.

A borehole grid is the current standard cavity detection technique in the site investigation process but is intrusive, non-continuous, slow, expensive, likely to miss cavities smaller than the borehole spacing (Kendorski, 2004) and can decrease the integrity of the subsurface. Visual site inspections and desk studies are useful but not conclusive. A robust cavity detection investigation standard is required and geophysical techniques offer an attractive alternative.

A range of geophysical techniques have previously been utilised successfully in the detection of cavities in various geologies: microgravity (Rybakov et al., 2001; Styles et al., 
2006; Tuckwell et al., 2008), resistivity (Rodriguez Castillo and Reyes Gutierrez, 1992; Elawadi et al., 2001; Roth et al., 2002), a variety of seismic techniques (refraction - Ballard et al., 1982; reflection - Miller and Steeples, 1991; surface wave diffraction - Xia et al., 2007), and recently multidisciplinary techniques (Filahi et al., 2008; Cardarelli et al., 2009; Pueyo-Anchuela et al., 2010).

Despite this, the industry is inclined to rely on well-established intrusive techniques and can be legally tied to certain borehole techniques (Styles, 2003). Compounding this, geophysics for cavity detection has an uncertain reputation in some areas of the engineering industry. Users often recall bad experiences with geophysical surveys: the target remained undetected despite assurances of detection; more questions were created than answers; or results were obscured by noise (EAGE Conference and Exhibition workshop discussion, 2012). Reasons for these experiences include: unfamiliarity with the techniques and subsequent unreasonable expectations; use of geophysics as a last resort when the subsurface is so complex that other techniques have failed; overselling of certain techniques to win tenders; or indiscriminate choice of particular techniques (EAGE Conference and Exhibition workshop discussion, 2012). Techniques that are viable on one site may not be applicable on another, and there is no consensus on which technique is suitable in a given situation, or if geophysics will be suitable at all. Comparison of the effectiveness of different geophysical techniques on sites that are commonly used by engineering companies is limited in the literature.

It is therefore imperative to outline the spectrum of where and when techniques work or do not. Currently cavity detection technique choice is largely heuristic which can be useful with experienced practitioners. However, the increased popularity and ease of use of geophysics means less experienced users are designing surveys and may choose inappropriate techniques. 'Rules of thumb' can be of use and are usually grounded in theory but too often are not used in conjunction with or presented alongside any intended constraints. The rules also vary vastly between sources; in gravimetry for example it is suggested that a cavity is detectable when the depth to diameter ratio is 8-10:1 (Butler, 2008), 2:1 (McCann et al., 1987) and 1:1 (U.S. Army Corps of Engineers, 1995). These rules provide an inherently simplistic approach to a feasibility assessment, where modelling and subsequent assessment provides a more accurate alternative, with the advantage of applying site specific parameters. Here we show that forward modelling of geophysical techniques and subsequent feasibility analysis in various geological situations can aid discriminate technique choice, improve survey design, and increase survey success. The feasibility of chosen techniques is assessed by calculating the probability of detection along theoretical survey profiles in any site specific conditions. This gives us the ability and judgement to rule out some, and possibly all, techniques and highlights the uses and limitations of geophysics. Different survey directions and a range of profile and survey spacings are modelled to find the most efficient survey design for the given site and target. The technique is tested on two case studies in the U.K.

\section{Methods}

We concentrate on cavities less than $15 \mathrm{~m}$ depth as this is the depth of interest of most geotechnical investigations (Roth et al., 2002). Six typical cavity shapes (Fig. 1) are modelled to give a more accurate representation of widespread manmade and natural subsurface environments than the more commonly modelled cuboid and spherical shapes. As collapse of karstic cavities in rock is considered a rare occurrence (Fehdi et al., 2010), we concentrate on modelling migrating void shapes which form in eroded bedrock cover, migrate upwards and cause collapse (Edmonds, 2008). Natural cavities can be air, water or sediment filled. Shafts and bell pits are modelled with a range of fill and lining materials. Since the $17^{\text {th }}$ century mines have been lined and capped with local available material including brick, slate, steel rimmed or wood (Roe, 2008), each a very different geophysical target. Fill material, if used, is usually the locally 
available material. Table 1 shows the range of host materials modelled, concentrating on those typical in the U.K., and the corresponding geophysical parameters. This variety of subsurface scenarios means prediction of the geophysical response to a particular cavity is difficult. Modelling allows the assessment of the theoretical response of different techniques in endless subsurface scenarios.
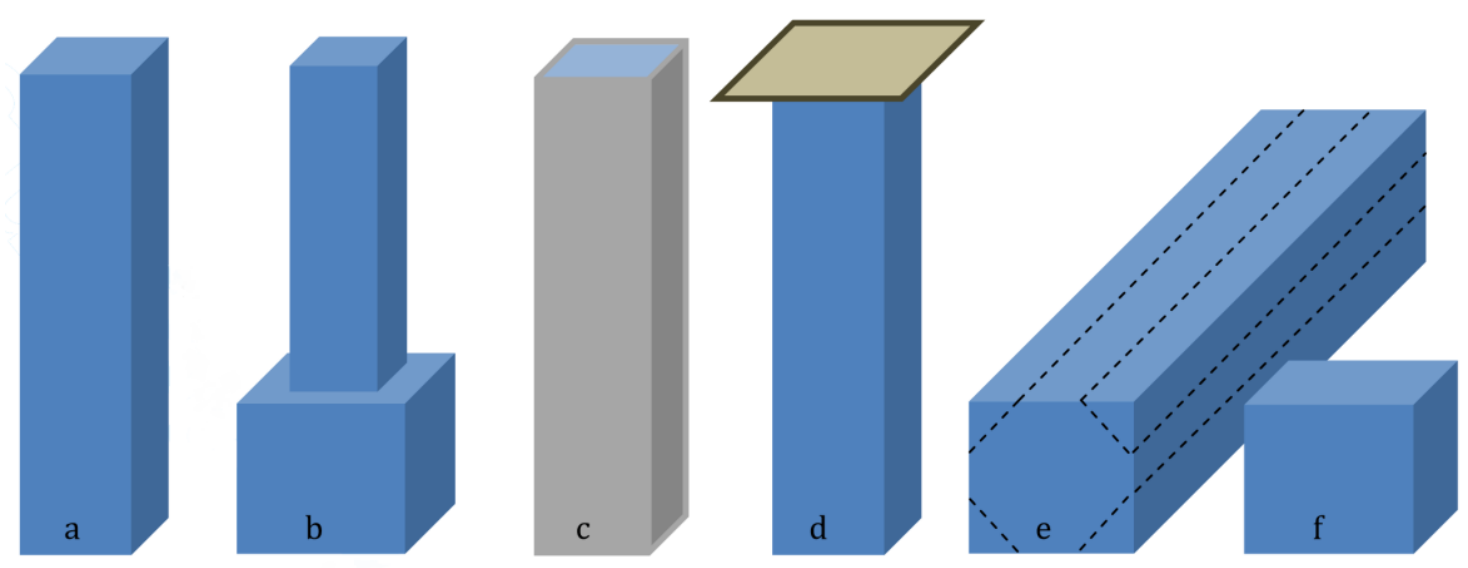

Figure 1. Typical cavity shapes used in modelling. a) shaft: shaft diameter increased through time up to $4 \mathrm{~m}$ wide and $250 \mathrm{~m}$ deep (Ove Arup and Partners, 1976). Circular shaped shafts were used in England, other regions (especially Scotland) used rectangular (Healy and Head, 1984). b) bell pit: bell pit diameter was usually around $1 \mathrm{~m}$ and depth was seam dependent but rarely over $12 \mathrm{~m}$ (Healy and Head, 1984). c) Lined shaft. d) Capped shaft. e) Horizontal gallery, representing natural cave systems or mines. The angle of dip can be altered and the prism can be adjusted (dotted lines) to better represent more rounded cavities (as tested in the West Wycombe case study). f) Cuboid: as in the case of a natural migrating void or a migrating void in a mine shaft as fill migrates to the roadways.

Table 1. Geophysical parameter values used in modelling. GPR is not modelled in soil or clay in this paper.

\begin{tabular}{llllll}
\hline \hline Material & \multicolumn{1}{c}{$\begin{array}{c}\text { Density } \\
\left(\mathbf{g} / \mathbf{c m}^{\mathbf{3}}\right)\end{array}$} & \multicolumn{1}{c}{$\begin{array}{c}\text { Magnetic } \\
\text { susceptibility }(\mathbf{k})\end{array}$} & $\begin{array}{c}\text { EM velocity } \\
(\mathbf{m} / \mathbf{n s})\end{array}$ & $\begin{array}{c}\text { Conductivity } \\
(\mathbf{m S} / \mathbf{m})\end{array}$ & $\begin{array}{c}\text { Dielectric } \\
\text { constant }\end{array}$ \\
\hline Limestone & $2.65^{2}$ & $0.000505^{2}$ & $0.12^{2}$ & $0.0001^{3}$ & $6^{2}$ \\
Soil & $1.92^{1}$ & $0.001^{3}$ & - & - & - \\
Sandstone & $2.35^{1}$ & $0.00002^{2}$ & $0.15^{4}$ & $0.01^{3}$ & $5^{3}$ \\
Clay & $2.21^{1}$ & $0.000255^{2}$ & - & - & - \\
Concrete & $2.3^{8}$ & $0.0017^{5}$ & $0.1^{6}$ & $0.001^{6}$ & $7^{7}$ \\
Air & 0 & $0^{2}$ & $0.3^{2}$ & $0^{2}$ & $1^{2}$ \\
Water & $1^{1}$ & $0^{2}$ & $0.033^{2}$ & $0.05^{2}$ & $80^{2}$ \\
\hline 1 - Seigel (1995). 2 - value or average of the range values listed in Milsom and Eriksen (2011). \\
3 - Erkan and Jekeli (2011). 4 - Martinez et al. (1996). 5 - McEnroe (1998). 6 - Reynolds \\
(1997). 7 - Carino (2010). 8 - Kosmatka (2010). \\
\hline
\end{tabular}

Modelling techniques

Five geophysical techniques are compared: gravimetry, gravity gradient, magnetometry, magnetic gradient and ground penetrating radar (GPR). Gravimetric methods were chosen for analysis as they are ranked the most commonly used and preferred method of cavity detection in Europe and third most popular in the U.S. (Butler, 2008). Similarly, electromagnetic methods (including GPR) are the most preferred in the U.S. and second in Europe (Butler, 2008), despite the limitations of penetration in conductive media. Numerous other sources highlight the applicability of these two techniques to cavity detection and offer examples of their successful 
application (e.g. Reynolds, 1997; Sharma, 1997; Anderson and Ismail, 2003). Magnetometry is less commonly associated with cavity detection as the susceptibility contrast between most geologies and an air or water cavity is very small. However, it is possible to detect such a cavity if the noise level is low enough (Manzanilla et al., 1994; Rybakov et al., 2005; Chamon and Dobereiner, 1988). Also, magnetometry is often used to detect filled natural cavities (Saribudak, 2001; Mochales et al., 2007) and especially cavities associated with mining where the discarded ferromagnetic material is often used to fill shafts, or caps and lining are installed (PueyoAnchuela et al., 2010; Raybould and Price, 1966). Magnetometry is therefore worth considering when attempting to detect cavities and is hence compared with the other techniques.

A subsurface model of the relevant geophysical parameters for each technique is created and the response from a range of geophysical techniques is modelled. Modelling the chosen underground cavities shapes in three dimensions allows calculation of detection probability over a range of survey parameters was of highest importance in choosing an appropriate modelling algorithm.

Although analytical solutions to gravity and magnetic anomalies of spherical and cylindrical shapes are well established (Parasnis, 1996), more complex shapes are required to represent the most common cavity types (Fig. 1). Addition of spheres and cylinders can go some way to representing complicated polygons (gravity method (Talwani and Ewing, 1960); magnetic method (Talwani, 1965)), but in the very near surface the resultant disparity in anomaly size and shape will be of importance to the detection probability. A more suitable method is modelling the potential field of a polyhedron made up of any number of polygons, allowing flexible creation of all the typical 3D cavity shapes. Algorithms calculate the volume integral of dipoles first over the surfaces of polyhedron (Barnett, 1976) and then, as used here, line integrals (Guptasarma and Singh, 1999). This algorithm is based upon the equality of the magnetic field of a polyhedron and the field of a surface distribution of magnetic pole density, which is equal to the normal component of magnetisation intensity. In practical terms the polyhedron field is calculated by translating each polygon face's surface integral into a line integral around the face edge. This method allows the use of any cavity shape that can be created by flat face polygons. Similarly, the field due to the distribution of surface mass density is shown to be equivalent to the field of a uniform density polyhedron (Singh and Guptasarma, 2001). The surface mass density is calculated on each face by the product of the body volume density and the scalar product of the unit vector normal to the face and the direction vector of the face to the current observation point.

Vertical gradient methods are suited to cavity detection as they are sensitive to subtle lateral changes in the field along a profile. Magnetic gradient measurements are common as many magnetometers have two sensors that can record concurrently. Gravity gradient techniques are less common in near surface geophysics because taking two measurements, one on each level of a two tier tower, at each survey point is time consuming and hence costly. The technique has been used successfully in cavity detection (Pánisová and Pašteka, 2009; Butler, 1984). The gradient is calculated by finding the difference between the potential fields at both sensors and dividing by the sensor separation (the default used is $1 \mathrm{~m}$ ).

The voltage recorded at the GPR receiver, and its amplitude compared to the site noise level, must be calculated to test the methods applicability to cavity detection. Methods for modelling GPR include: ray tracing (e.g. Cai and McMechan, 1995); finite difference time domain methods which can incorporate a range of frequencies but are slow in computation (e.g. Roberts, 1997; Uduwawala and Norgren, 2004); and the radar range equation, utilised here, that offers a simple analysis of signal amplitude losses in a given environment (Daniels et al., 1988). A subsurface variation of the radar range equation (Daniels, 2004) determines the voltage received by calculating the loss of energy through attenuation as an electromagnetic wave propagates through the subsurface. 


$$
v(r, \eta)=\frac{V_{0} A \sigma \kappa}{c r^{\prime 2} \tau} \tau_{g} \rho_{t} 10^{-3} e^{(-2 k r)}
$$

Where, $\mathrm{V}_{0}=$ peak radiated voltage $(\mathrm{V}), \tau=$ pulse duration (seconds), $\mathrm{c}=$ speed of light $(\mathrm{m} / \mathrm{s}), A=$ antenna effective aperture $\left(\mathrm{m}^{2}\right), \sigma=$ target cross section $\left(\mathrm{m}^{2}\right), \kappa=$ number of averages, $\tau_{\mathrm{g}}=$ transmission coefficient into subsurface, $\rho_{\mathrm{t}}=$ target reflection coefficient, $\mathrm{k}=$ propagation coefficient, $\mathrm{r}=$ range $(\mathrm{m}), \mathrm{r}$ '=equivalent range taking antenna beam pattern into account. The radar parameters used in the calculation were calculated based on values for the Sensors and Software PE100A GPR (Sensors Software Inc., 2003). It should be noted this radar range technique is primarily aimed at use beyond $2 \mathrm{~m}$ depth (Daniels, 2004) and is not a full waveform model.

\section{Site specific noise level}

Noise level varies between techniques and sites but subtle cavity signals can easily be obscured in all techniques. Frequency and space filtering may be used to eliminate the effects of noise but filtering is limited in its ability to distinguish between noise and features (being based solely on wavelength or width) and can distort the shape of genuine signal pulses or even create artificial anomalies (Parasnis, 1996; Salem et al., 2010). To avoid losing subtle cavity signals in processing, the original, noisy data must often be used. If it can be established that the signal from the chosen target is significantly greater than the expected noise on a site, a positive detection of the cavity can be expected. Therefore, site noise level must be found. Though noise level varies between sites, a scale of typical noise levels, from rural, through brownfield, to urban, can be classified. Measuring the noise level on individual sites is preferable but if the site is in use or inaccessible, site noise must be estimated from relevant literature or from measurements at similar sites.

Magnetic noise measurements were taken on a range of typical sites and covering the spectrum of potential noise (Fig. 2). Measurements were taken with a Geometrics G-858 magnetometer in gradiometer mode in order to negate diurnal change. The general trend of the magnetic field was noted and the standard deviation from this trend gave the noise level at each location. The sites are grouped into four categories: greenfield, urban and buildings, brownfield, and indoor with average noise levels of $0.55 \mathrm{nT}, 13.65 \mathrm{nT}, 18.39 \mathrm{nT}$ and $21.21 \mathrm{nT}$ respectively (Fig. 2). This range in site noise level will have a large influence on the cavity detection probability in different environments. This measurement method of noise estimation is much more precise than using a single "typical" value of noise for all sites or not considering noise level at all, as is often the case in other modelling. Similar studies for other techniques should follow.

\section{Probabilistic approach to detection in noise}

The detection probability is calculated to assess and compare the suitability of each technique in any given subsurface, noise level and survey condition. The basis of this calculation is the comparison between the level of meaningful signal as a result of the cavity, and the estimated or measured level of unwanted noise at the site represented by random noise of that amplitude. The signal amplitude resulting from the cavity at each survey point across the site is calculated using the chosen algorithm for each technique. The probability of isolation of the signal anomaly from unwanted noise present in a dataset is calculated following Kotelnikov's criterion (Fajklewicz et al. (1982) apud Nikitin and Tarchov (1973)): 


$$
\text { Detection probability }=\frac{1}{\sqrt{2 \pi}} \int_{0}^{\frac{\sqrt{\alpha}}{2}} \frac{-t^{2}}{e^{2}} d t
$$

Where $\alpha$ is the amplitude charateristic of the anomaly and $t$ is the integrated variable. The modelling simulates the anomaly shape and amplitude and the amplitude characteristic is calculated thus:

$$
\alpha=\frac{\sum_{i=1}^{m} A^{2}\left(x_{i}\right)}{\hat{\sigma}^{2}}=\frac{\bar{A}^{2} \cdot m}{\hat{\sigma}^{2}}
$$

Where $\mathrm{A}\left(\mathrm{x}_{\mathrm{i}}\right)$ is the anomaly at point $\mathrm{x}_{\mathrm{i}}$ along a profile caused by the cavity, $\mathrm{m}$ is the number of measurements and $\hat{\sigma}$ is the dispersion of the measurements or the noise level on the site. Equation 2 can be simplified to the 'error function', and so the detection probability of an anomaly of known form and intensity in noise simplifies to:

$$
\text { Detection probability }=\operatorname{erf}(\sqrt{\rho / 2})
$$

Where $\rho$ is the ratio of the anomaly square to the noise dispersion and erf is the error function. This calculation has been previously utilised with respect to geophysical fields in Khesin et al. (1996) and in 2D modelling by Erkan and Jekeli (2011).

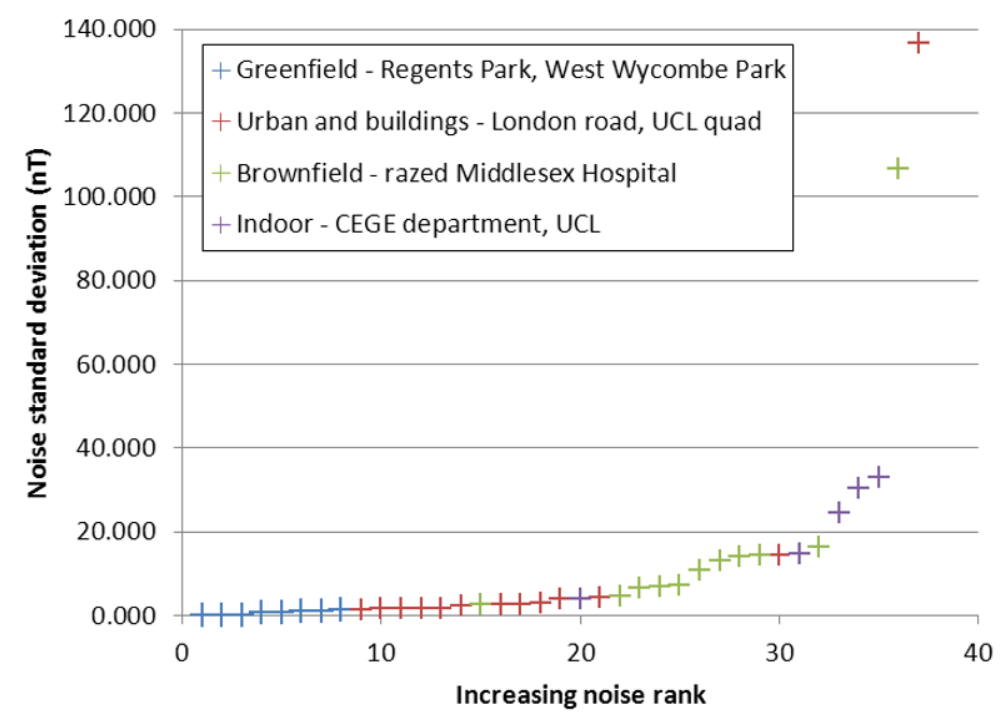

Figure 2. Noise level variation with site type.

Geophysical surveys generally consist of more than one profile and so the overall detection probability of all survey profiles together must be calculated. This allows analysis of the effect on detection probability of altering survey size, profile spacing or survey point spacing. We can subsequently calculate the optimum survey parameters for detection. The probability of cavity detection is assessed on every survey line using Kotelnikov's criterion (Equation 4). As GPR records a signal possible of delineating a cavity at each survey position, the detection probability is calculated at every survey point. Since each survey line can be considered a statistically independent event, the probability of detection on at least one of the survey lines is the complement of the probability of no-detection on all lines:

$$
P(\text { detection on any of the survey lines })=1-P(\text { no detection })
$$


Where $P($ no detection $)=\left(1-P\left(\right.\right.$ detection $\left.\left._{\text {line }} \quad 1\right)\right) \times\left(1-P\left(\right.\right.$ detection $\left.\left._{\text {line }} \quad 2\right)\right) \times \ldots \times(1-$ $P\left(\right.$ detection $\left.\left._{\text {line }}\right)\right)$ ), and $\mathrm{n}$ is the number of survey lines. It is unreasonable to assume that the central survey line will be directly above the cavity (the best case scenario), and so the effect of altering the survey starting position is investigated. The Monte Carlo method of stochastic sampling is applied to calculate an unbiased value of the overall probability. Survey profile start positions are varied randomly between the best case (aforementioned) and the worst, in which the cavity lies directly between two consecutive survey lines. As gravity measurements are taken discretely along profiles (where GPR and magnetic techniques take measurements almost continuously), both the profile and station start positions are varied. The average detection probability of 100 surveys with random start positions is calculated for any chosen profile or station spacing. The modelled signal of each technique is visualised as a $3 \mathrm{D}$ surface across the survey space with the detection probability of each profile indicated by line shade.

\section{Results}

Figure 3(a) shows the modelled result of a magnetic survey over a $1 \mathrm{~m}$ sided cube air cavity at $3 \mathrm{~m}$ depth in limestone with typical noise levels (Table 2). The cavity detection probability is over $20 \%$ on each survey line up to $3 \mathrm{~m}$ from the cavity centre but decreases rapidly beyond this. The same cavity is modelled in a range of geologies and depths (Fig. 3(b)). Cavity detection probability on the central survey line decreases as cavity depth increases in a similar manner for all geological materials but the probability varies greatly between materials because of the variation in host susceptibility.

a)

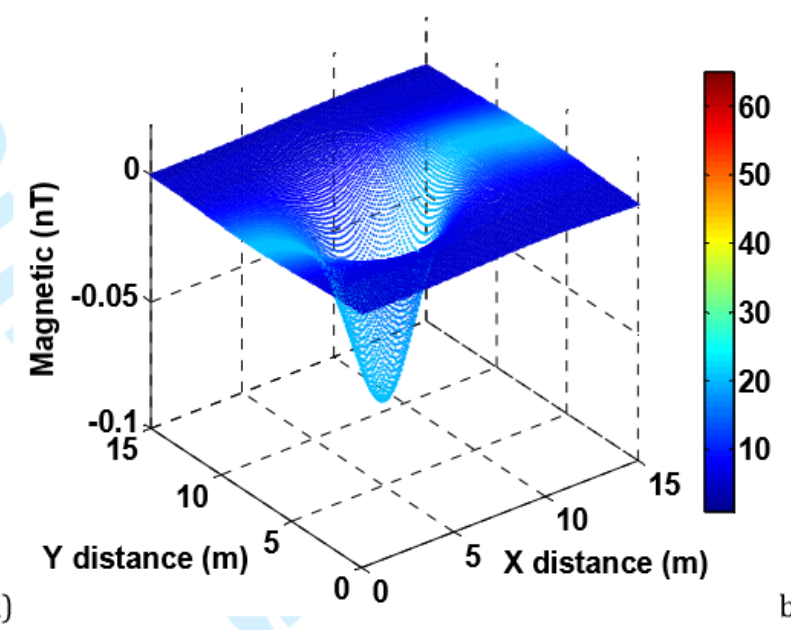

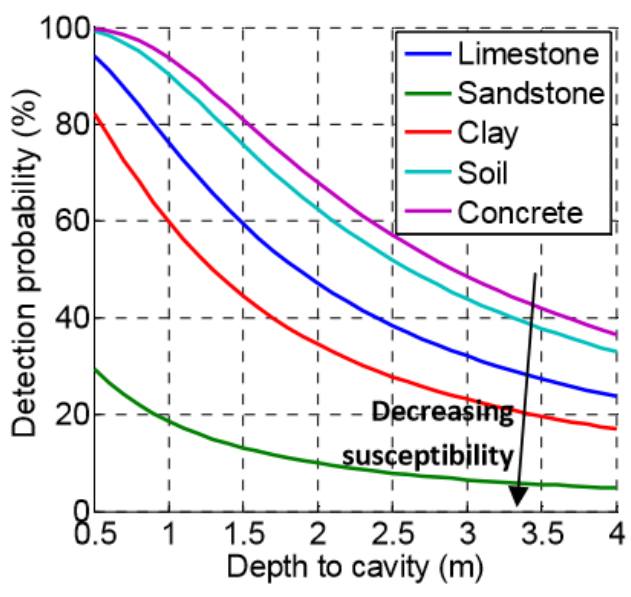

Figure 3. a) Modelled results showing the probability of detection of a $1 \mathrm{~m}$ sided cube air cavity at $3 \mathrm{~m}$ depth in limestone using magnetometry. The colour bar indicates the probability of detection in typical magnetic noise (Table 2). b) The detection probability of the same cavity decreasing with depth in a range of geologies. The probabilities shown represent that of a survey line directly above the cavity.

Extending the modelling to calculate the probability over a survey grid, Fig. 4 shows an example of the modelling output of all techniques over a $1 \mathrm{~m}$ sided cube water cavity at $2 \mathrm{~m}$ depth in sandstone. Detection probability on individual profile lines decreases rapidly with distance from the cavity. Overall detection probability on the $15 \mathrm{~m}$ grid is low at these typical noise levels for the magnetic, magnetic gradient and gravity methods. The small contrast in density between water and sandstone decreases the gravity anomaly and low susceptibility of sandstone decreases the magnetic anomaly size. 

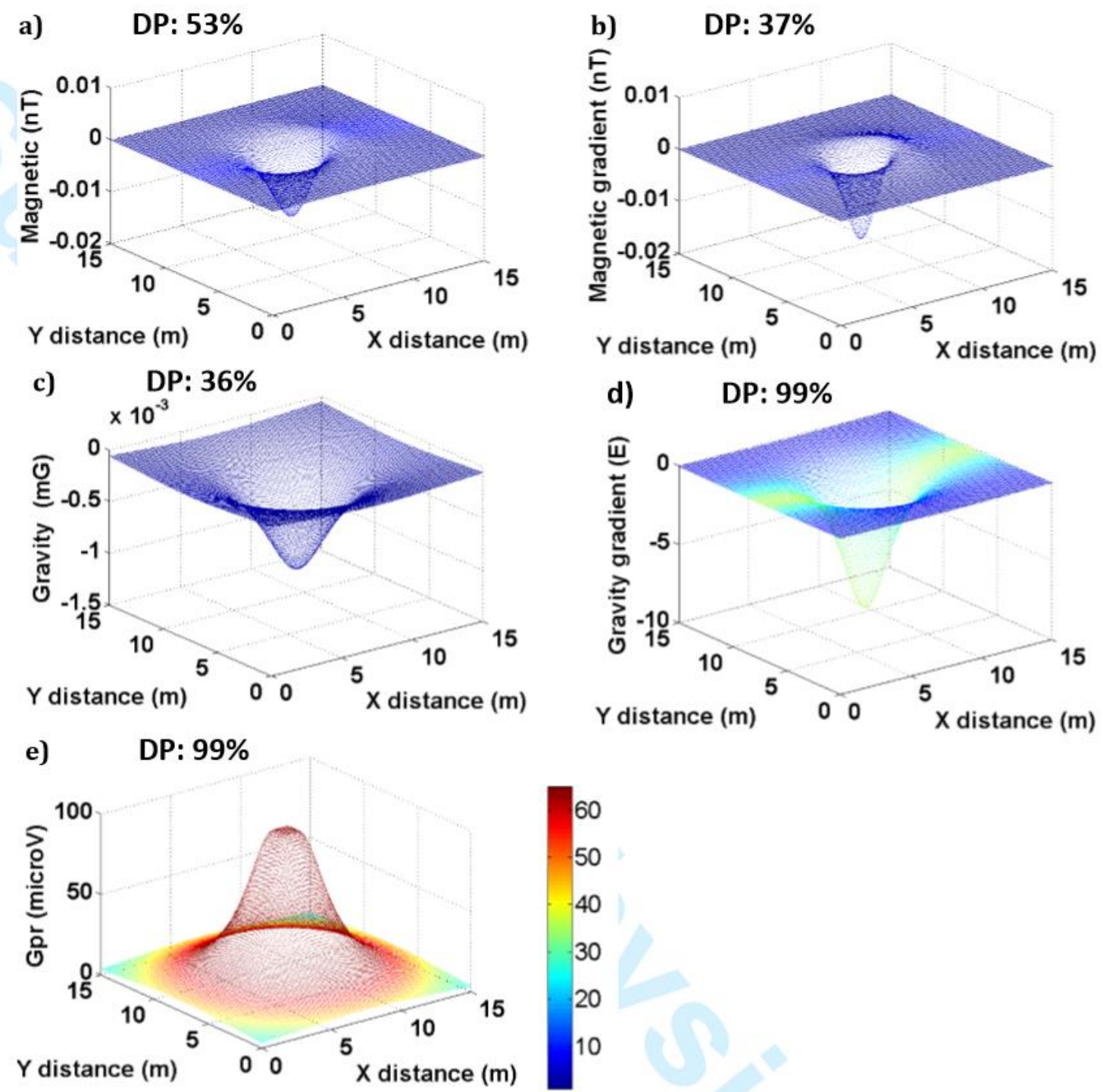

Figure 4. The cavity is a $1 \mathrm{~m}$ sided cube water cavity at $\mathbf{2} \mathrm{m}$ depth in sandstone modelled with a) magnetic, b) magnetic gradient, c) gravity, d) gravity gradient, e) GPR. Overall detection probability is shown above each technique and the colour bar indicates profile line detection probability. DP = overall detection probability.

The amplitude, wavelength and shape of an anomaly over a cavity depend on numerous parameters. Here, we alter various subsurface parameters to monitor the effect on the anomaly and the detection probability.

\section{Profile and station spacing}

Profile and station spacing judgment is of great importance in survey design. An optimum design will detect the target with the least amount of stations possible, saving time and money. The minimum spacing required to detect a cavity to a certain confidence interval can be calculated with this modelling approach. Figure 5 shows the modelled signal of the magnetic, gravity, gravity gradient and GPR techniques for a $3 \mathrm{~m}$ deep, $1 \mathrm{~m}$ cube air cavity in limestone across a $15 \mathrm{~m}$ survey grid. The maximum responses are small for all techniques (amplitudes of $0.08 \mathrm{nT}, 0.0013 \mathrm{mGal}, 8.3 \mathrm{E}, 26 \mu \mathrm{V}$ ) but at typical noise levels (Table 2) the detection probability is over $50 \%$ for the gradient gravity and GPR methods on the central profiles. 

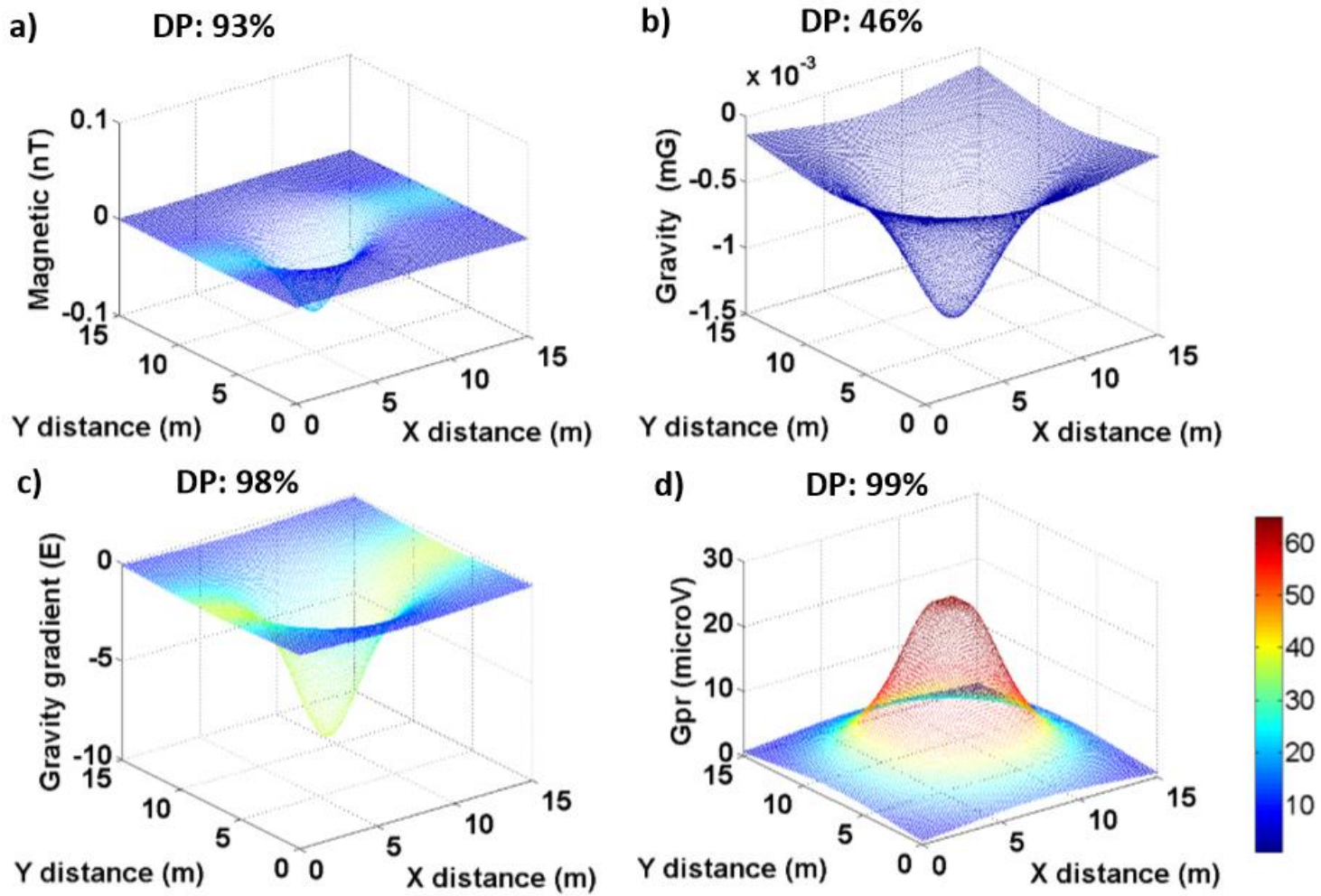

Figure 5. Theoretical response to a $1 \mathrm{~m}$ cube cavity at $3 \mathrm{~m}$ depth in limestone over a $15 \mathrm{~m}$ square grid by: a) magnetometry, b) gravity, c) gravity gradient and d) GPR techniques. The colour bar indicates the detection probability for each survey line. DP = overall detection probability.

To assess the optimum survey design, the detection probability is calculated with a range of profile spacings (Table 2). The probability of detection falls quickly as spacing is increased but the decrease is variable between techniques. Increasing spacing from $1 \mathrm{~m}$ to $2 \mathrm{~m}$ decreases the total detection probability by: 24\% (GPR), 19\% (gravity), 20\% (magnetic) and 1\% (gravity gradient). Increasing spacing to $3 \mathrm{~m}$ decreases detection probability a further: $14 \%$ (magnetic), 9\% (gravity) and 8\% (gravity gradient) and 34\% (GPR). With $2 \mathrm{~m}$ spacing, the gravity gradient method has over $95 \%$ chance of cavity detection and is hence suitable for use in this situation. Spacing intervals are limited to $1 \mathrm{~m}$ as these are the easiest to set up in the field, though more accurate spacings can be calculated for use with, for example, a robotic survey setup.

Table 2. Effect of increased spacing. Detection probability (\%) of a range of techniques with increasing survey spacing. Darker shade represents a higher detection probability.

\begin{tabular}{lllccc}
\hline \hline \multicolumn{1}{c}{ Technique } & \multicolumn{3}{c}{ Noise } & \multicolumn{3}{c}{ Spacing } \\
\cline { 3 - 5 } & & $\mathbf{1 m}$ & $\mathbf{2 m}$ & $\mathbf{3 m}$ \\
\hline Magnetic & $0.1 \mathrm{nT}$ (Geoscan Research 2012) & 93 & 73 & 59 \\
Gravity & $0.1 \mathrm{mGal}$ (Laswell et al. 2008) & 46 & 27 & 18 \\
Gravity gradient & $3 \mathrm{E}$ (Erkan and Jekeli 2011) & 98 & 97 & 91 \\
GPR & $10 \mu \mathrm{V}$ (Erkan and Jekeli 2011) & 99 & 75 & 41 \\
\hline
\end{tabular}

Noise level

Figure 6 shows the modelled magnetometry detection probability of an air shaft $(1 \mathrm{~m}$ square, $6 \mathrm{~m}$ in height) at $1 \mathrm{~m}$ depth in the 4 aforementioned noise levels measured in the field. 
At the greenfield noise level detection probability of the shaft is above the standard $95 \%$ confidence interval. At all other noise levels the probability of cavity detection is very low and hence the magnetic method is inapplicable. These tests highlight the importance of site specific noise level consideration in near surface modelling, a step that is rarely taken.

a) DP: $95 \%$

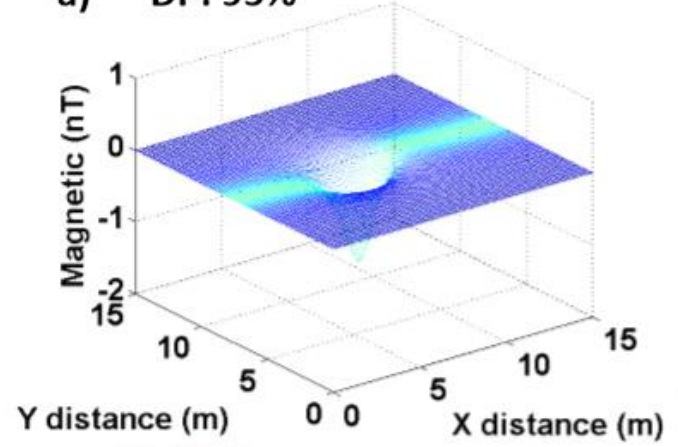

c) DP: $36 \%$

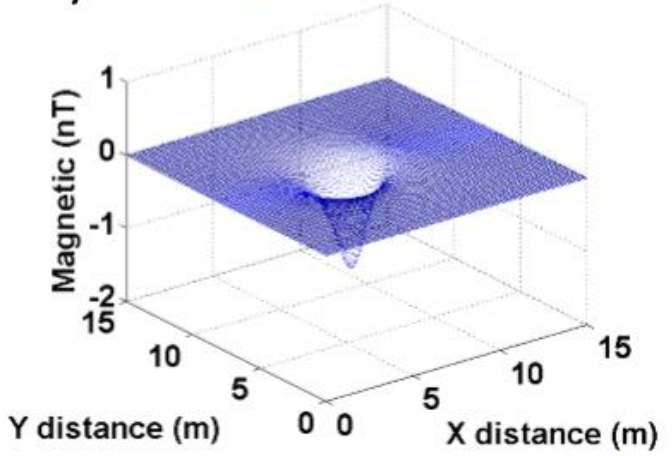

\section{b) DP: $41 \%$}

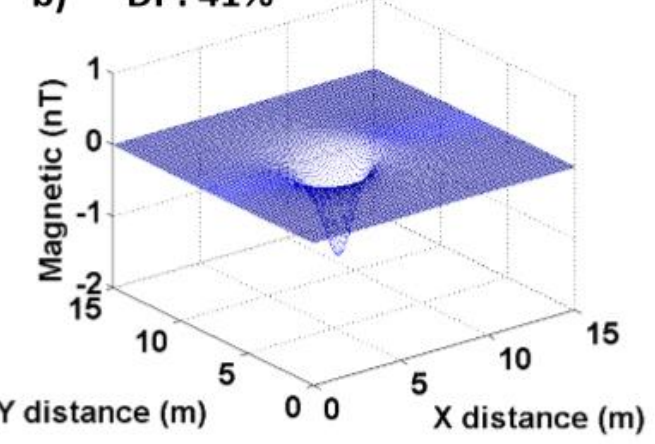

d) DP: $34 \%$

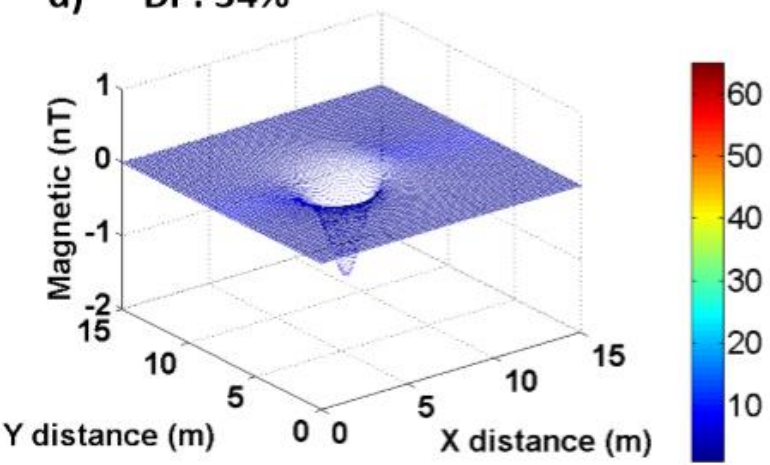

Figure 6. Modelled magnetometer signal of a $1 \mathrm{~m}$ square and $6 \mathrm{~m}$ tall air shaft in limestone at $1 \mathrm{~m}$ depth in different noise conditions: a) greenfield, b) urban and buildings, c) brownfield and d) indoor. The colour bar indicates profile detection probability (\%). DP = overall detection probability.

\section{Data deletion percentage}

During data processing, a number of noisy data points may need to be deleted because of noisy anomalies (e.g. spikes in magnetic data or incorrectly coupled resistivity spikes). The effect of this data deletion on detection probability is considered. The potential techniques were modelling over a $1 \mathrm{~m}$ cube air cavity at $3 \mathrm{~m}$ depth in limestone with $2 \mathrm{~m}$ spacing at typical noise levels (Table 2). The data deletion had a more pronounced effect on detection probability for the gravity techniques which record fewer points along the survey line than the magnetic techniques which, even after data deletion still had a large number of survey points close enough to the target to record a high amplitude signal (Fig. 7(a)). As data detection percentage was raised to $75 \%$ detection probability fell by up to: $9.5 \%$ (gravity), $14 \%$ (gravity gradient), $2.5 \%$ (magnetic) and $3.4 \%$ (magnetic gradient).

The variance of detection probability over 100 simulations with random starting positions increased with data deletion and spacing (Fig. 7(b)). Over the 100 simulations, the gravity detection probabilities were spread over a range of $12.4 \%(1 \mathrm{~m}$ spacing) and $7.9 \%(2 \mathrm{~m}$ spacing) at $75 \%$ data deletion. These results indicate that when a high level of data deletion is expected or spacing is large the detection probability becomes less reliable. 
a)

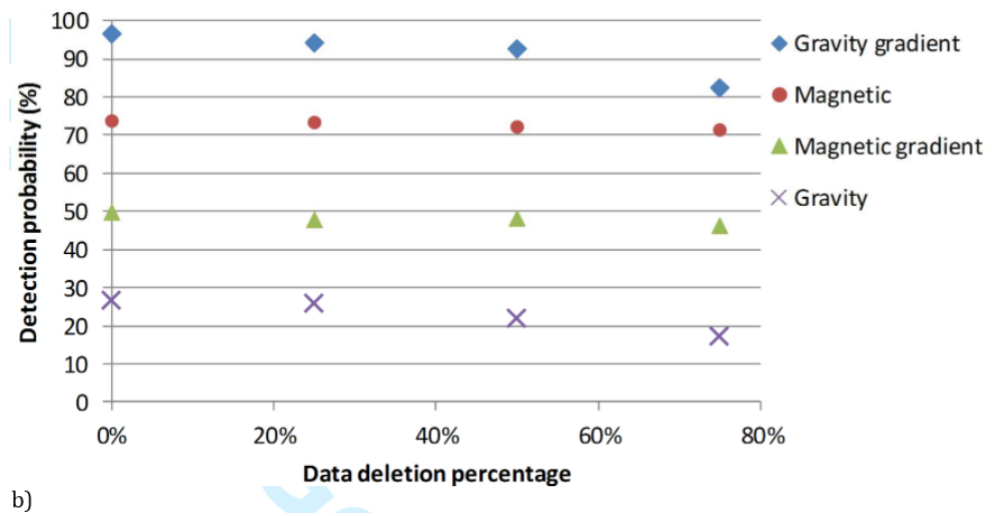

b)

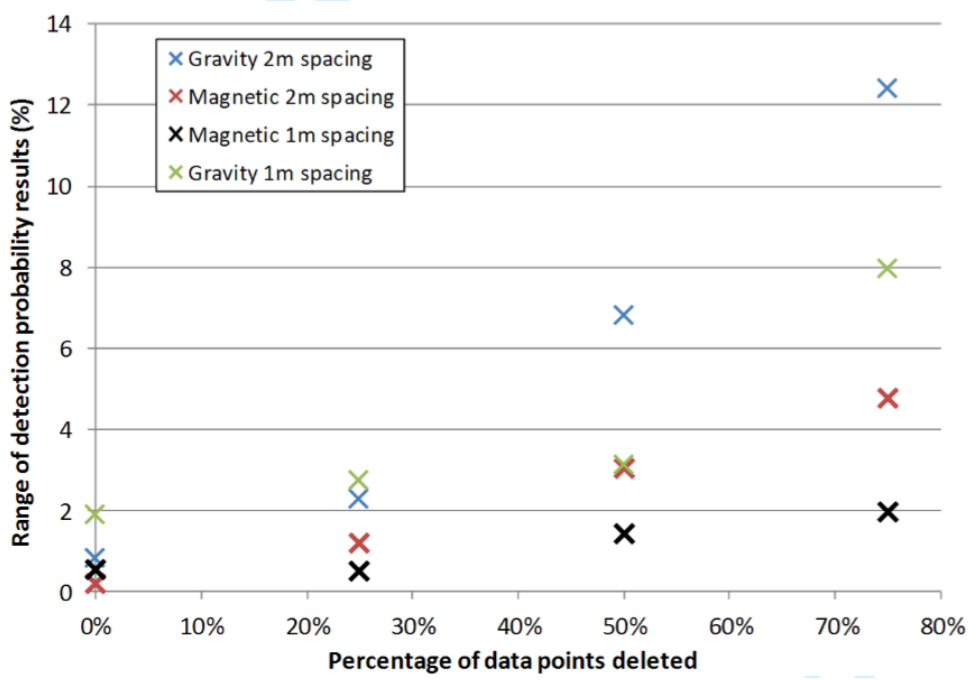

Figure 7. a) Detection probability decreasing with increased data deletion for potential techniques over a $1 \mathrm{~m}$ sided air cube at $3 \mathrm{~m}$ depth in limestone in typical noise with $2 \mathrm{~m}$ profile spacing. b) Variance of detection probability over 100 simulations over the same cavity.

\section{Cavity shape}

The effect on detection probability of changing cavity shape and fill is tested (Fig. 8) (an example of a dipping gallery model is seen in the West Wycombe Cave case study). The magnetic and gravity methods are modelled over the cavity shapes at $1 \mathrm{~m}$ depth in limestone at typical noise levels. Using the magnetic method, an air filled shaft and a water shaft are equally detectable, but the higher density contrast of an air shaft translates to an $8 \%$ difference in detection probability using the gravity method. The addition of steel lining and shaft cap increases detectability using the magnetic method across the whole site. With the gravity method, the small amount of steel in the cap complicates the signal from the air shaft, lowering the maximum and minimum amplitudes and subsequently decreasing the detection probability. When the shaft is lined and capped the additional dense material in the subsurface results in a positive anomaly and a 5\% detection probability increase using the gravity method. A bell pit beneath the shaft increases the detection probability for both techniques, though has a larger effect on the gravity method. 


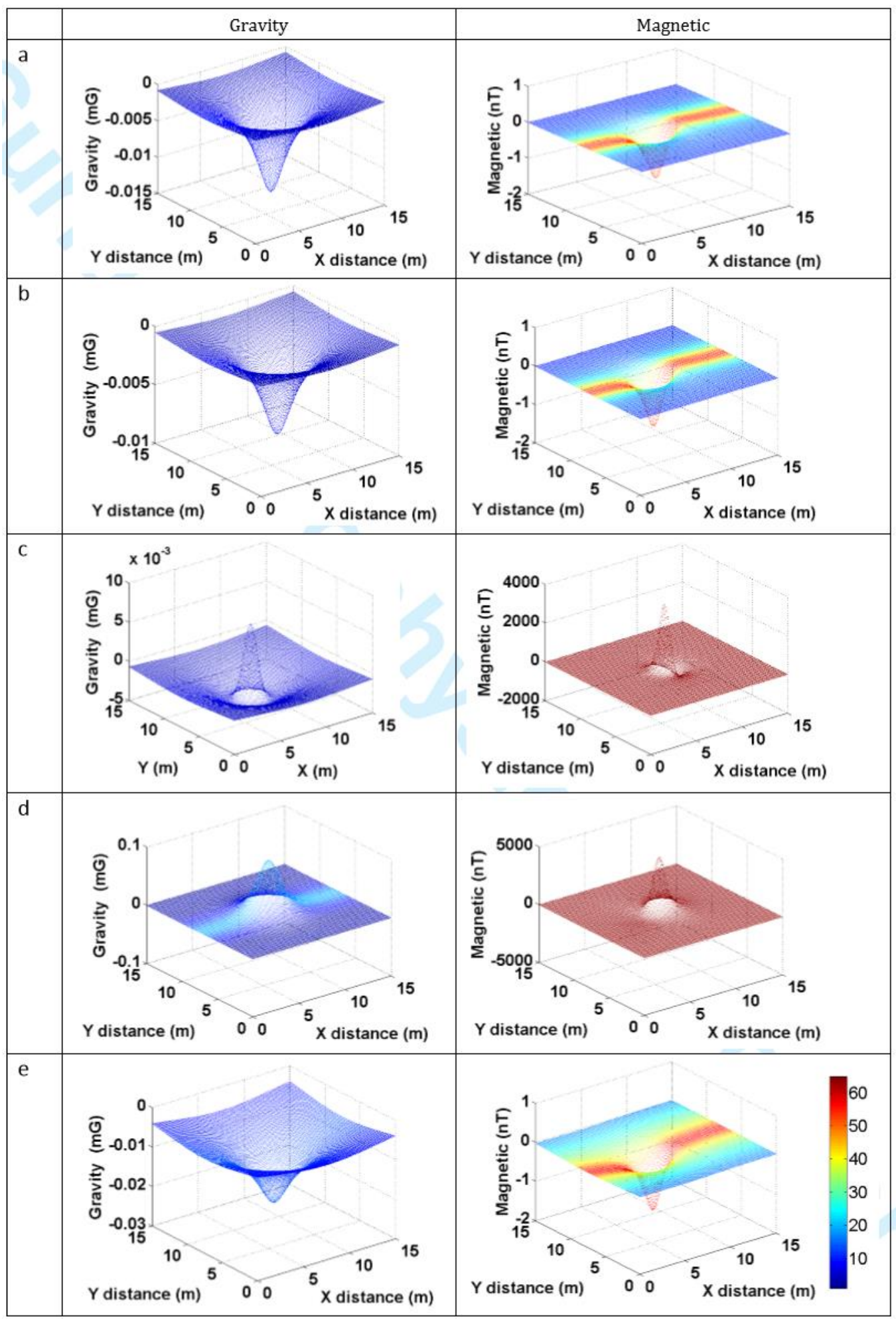

Figure 1. Modelled signal over typical cavity shapes in limestone. A $1 \mathrm{~m}$ square, $1 \mathrm{~m}$ deep, $6 \mathrm{~m}$ tall a) air shaft, b) water shaft, c) air shaft with $0.5 \mathrm{~m}$ steel cap, d) air shaft with steel lining and cap $(0.5 \mathrm{~m})$, and e) air shaft with $4 \mathrm{~m}$ square, $2 \mathrm{~m}$ tall bell pit beneath. The colour bar indicates detection probability (\%).Survey lines are indicated with black lines.

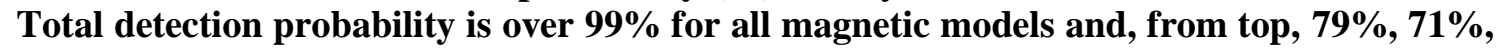
$\mathbf{7 2 \%}, \mathbf{8 4 \%}$ and $94 \%$, for gravity. 
These examples show the significant effect that cavity shape and makeup have on detection probability. Endless other subsurface conditions can be modelled, and detection probabilities calculated for all techniques, giving an accurate assessment of the feasibility of incorporating geophysics into a project.

\section{Magnetic survey direction}

At any latitude the peak to peak amplitude of a magnetic anomaly is largest when measured in the north-south direction (Breiner, 1999). This often justifies the orientation of a magnetic survey in the north-south direction (Scollar et al., 2009; David, 2008). However, here it is shown that a survey in this direction is not always optimal. Figure 9(a) shows the contoured modelled total magnetic field over a $1 \mathrm{~m}$ air cube at $3 \mathrm{~m}$ depth in limestone. In a given level of noise, only signal above certain amplitude will be detectable and so the contour shapes indicate the region that a signal of that level is detectable. For example, the $0.001 \mathrm{nT}$ contour spreads across most of the survey site; if this is the lowest signal detectable at a given noise level (too subtle in reality) then a profile running through this contour will detect the target. Contour extents in the east-west and north-south direction are measured (Table 3) and the direction most likely to detect the target is inferred by the survey direction with the largest span.

For smaller signal levels (up to $0.001 \mathrm{nT}$ ) the anomaly is wider than long and so a survey in the north-south would be more successful. However, above this level the anomaly is longer than wide and so an east-west survey is more appropriate. This is clarified by calculating the detection probability using the cavity detection modelling algorithms at different noise levels. Fig. 9(b) shows the detection probability of a survey running east-west minus a survey running north-south. An east-west survey is always more likely to detect the example cavity than a north-south survey above $0.1 \mathrm{nT}$ noise. The peak difference occurs at $0.8 \mathrm{nT}$ noise when an east-west survey is $2.3 \%$ more likely to detect than a north-south. The difference then decreases as the length and width of the anomaly become more similar at higher signal levels (Fig. 9(a)).

\begin{tabular}{|c|c|c|c|}
\hline \multicolumn{4}{|c|}{$\begin{array}{l}\text { Table 3. Comparison magnetic of anomaly size } \\
\text { (Fig. 9) width and length at different signal levels } \\
\text { to assess the optimum survey direction. }\end{array}$} \\
\hline \multirow{2}{*}{$\begin{array}{c}\text { Signal level } \\
\text { (nT) }\end{array}$} & \multicolumn{2}{|c|}{ "Anomaly size (m) } & \multirow{2}{*}{$\begin{array}{l}\text { Difference } \\
\text { (m) }\end{array}$} \\
\hline & Width & Length & \\
\hline 0.0005 & 28.0 & 24.3 & -3.7 \\
\hline 0.001 & 22.1 & 20.1 & -2.0 \\
\hline 0.002 & 15.9 & 16.5 & 6 \\
\hline 0.003 & 12.6 & 14.4 & 1.8 \\
\hline 0.04 & 10.1 & 13.0 & 2.9 \\
\hline
\end{tabular}

\section{Limit of detection}

If potential cavity details are limited, the limitations of using geophysical techniques can be assessed by calculating the minimum cavity size detectable at a range of depths in any given geology. At each depth the cavity dimensions are increased until the cavity detection probability for each technique equals a chosen confidence interval, thus the minimum sized detectable cavity at the current depth is found. This informs site specific feasibility assessment of geophysical techniques. The optimum spacing to achieve the required detection probability can be calculated in this process as before. 
a)

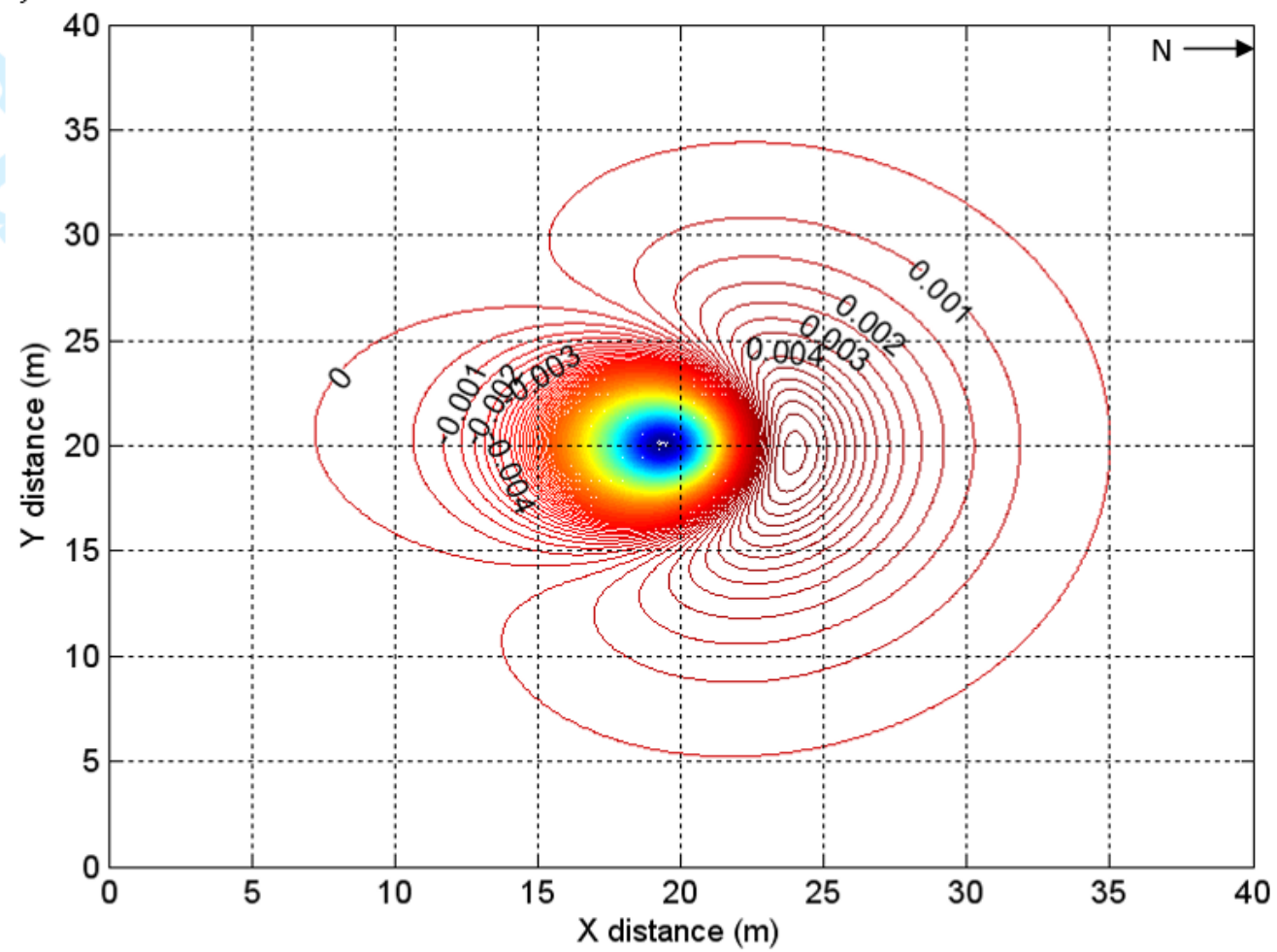

b)

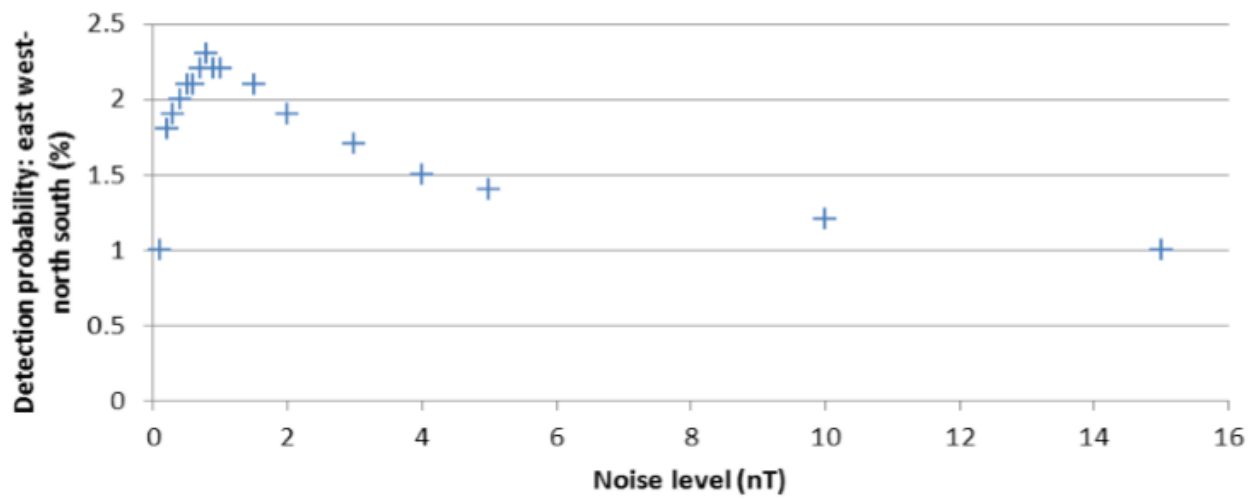

Figure 9. a) Plan view of a modelled magnetic field contours over a $1 \mathrm{~m}$ sided air cube at $3 \mathrm{~m}$ depth in limestone. Although detection at the level of signal indicated by the contours (down to $0.0005 \mathrm{nT}$ ) is unachievable in the field, the contours show the expanse of each level of signal across the site. The shape will be similar for higher magnitude anomalies dependent on the depth, size and makeup of the cavity and can be scaled up appropriately. b) Difference between the detection probability of a magnetic survey running east-west and a survey running north-south over the same cavity. A positive result indicates the east-west survey has a higher detection probability. The shape and amplitude of this graph will change dependant on cavity type and subsurface environment.

For the magnetic technique, the minimum detectable cavity cube size is calculated for range of parameters (Fig. 10). By altering each variable independently the effect on the cavity detection probability is highlighted. The variation in Fig. 10(a) is dominated by the difference in magnetic susceptibility of the host materials (Table 1). The low susceptibility of sandstone means a cavity has to be much larger at depth to be detectable than in other materials. Gravity is similarly affected by changes in material density and GPR by variation in dielectric constant and 
conductivity. Site noise level has the largest influence on the minimum detectable cavity size; a $1 \mathrm{~m}$ cube cavity at $5 \mathrm{~m}$ depth would have to be 2.4 times bigger to be detected in a typical noise level than at instrumental noise level, and 8.6 times larger to be detected in brownfield noise conditions. The effect of changing each parameter is intuitive but modelling allows accurate determination of these trends for a chosen techniques in given site conditions. The cavity size required for detection increases with depth significantly more rapidly in some subsurface conditions than others. For example the increase in noise level to brownfield level is much greater than the increase to the lower noise levels and so the detection probability decreases much faster. The effect of changing some parameters is negligible (e.g. increasing spacing above $4 \mathrm{~m}$, and data deletion over 10\%).

By modelling a combination of all these variables, the most suitable technique and survey parameters required to detect any given cavity to a prescribed confidence interval can be established.
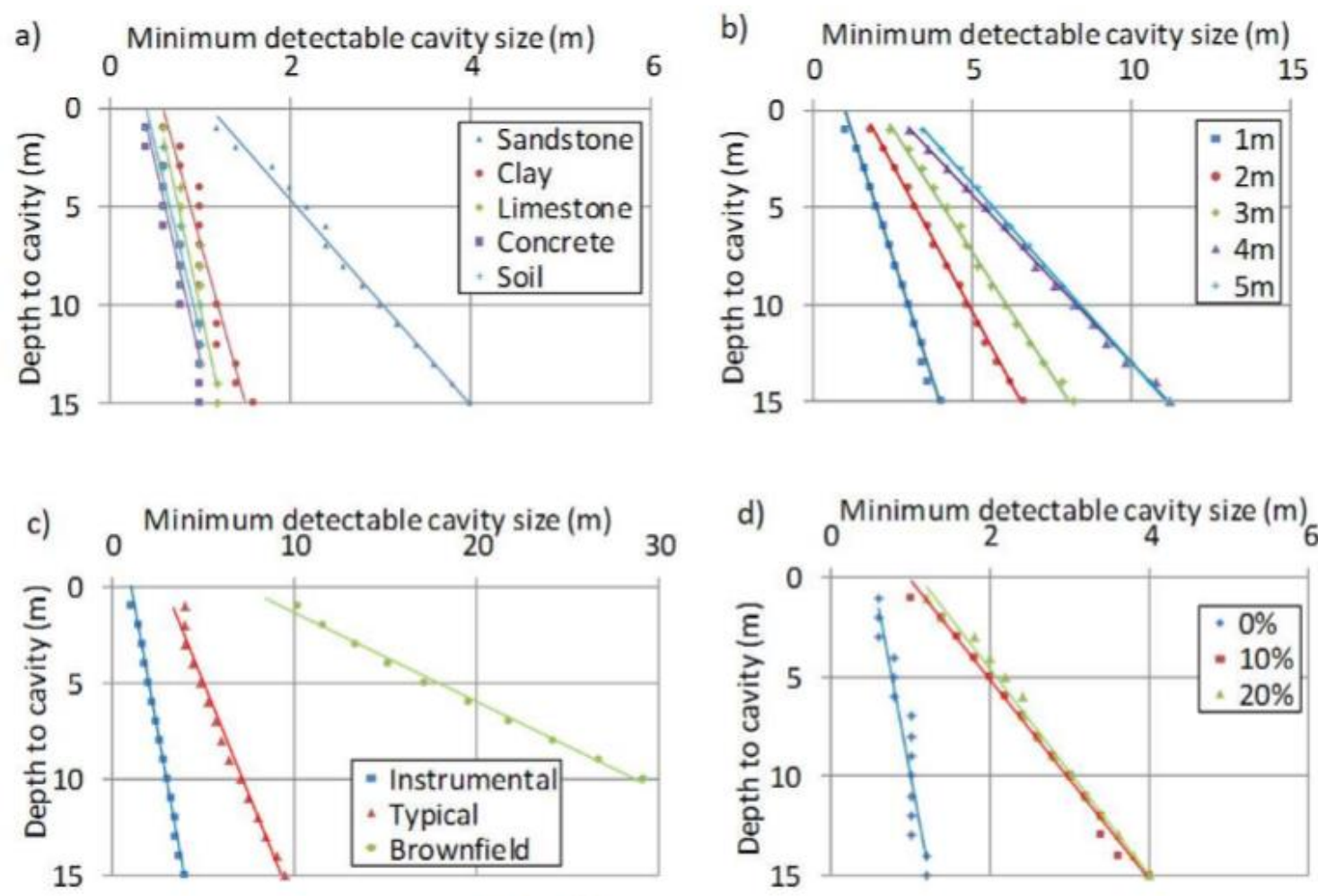

Figure 10: Change in minimum detectable cavity size with depth using the magnetic method. Base conditions were a cube void (with side length represented by the $x$-axis on the plots) in limestone at instrumental noise, $1 \mathrm{~m}$ line spacing and $0 \%$ data deletion, detected to $95 \%$ reliability. Altered parameters were: a) geology, b) profile line spacing, c) noise level and d) processing data deletion percentage. Cavity size was increased at $0.2 \mathrm{~m}$ increments causing some linear grouping of data; a linear best line was added across the data to find the overall trend. Susceptibility values as in Table 1.

Figure 11 shows the smallest cube detectable (to $95 \%$ reliability) in limestone from $0 \mathrm{~m}$ to $15 \mathrm{~m}$ depth using: GPR, gravity gradient, gravity and magnetics. This type of visualisation demonstrates clearly the feasibility of using each technique in these conditions. GPR and gravity gradient are seen to detect much smaller cavities at depth than the magnetic and gravity techniques. 


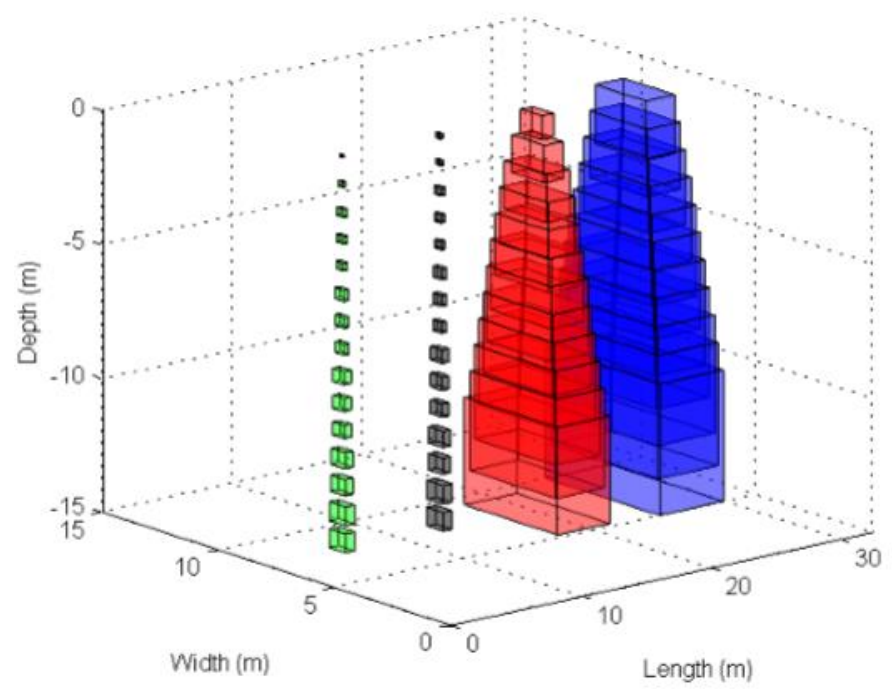

Figure 11. The smallest cube detectable (to $95 \%$ reliability) in limestone at depths from 0 $15 \mathrm{~m}$ using geophysical techniques.

\section{Middlesex Hospital case study}

Two case studies have been chosen utilising the modelling to aid technique and parameter choice. A mixed used development has been proposed on the now vacant site of Middlesex Hospital, Central London. During site excavation, empty under-pavement vaults were encountered around some of the site perimeter; other potential vaults required delineation.

The vaults were modelled to find the most suitable geophysical technique for the site. The dimensions were based on measurements taken on a previously exposed pavement vault on the site: $0.8 \mathrm{~m}$ deep, $1.5 \mathrm{~m}$ tall, and $2.8 \mathrm{~m}$ across. Typical brownfield levels of noise were chosen as the survey line is next to a road and a construction site (values from McCann et al., 1987; United States Army Corps of Engineers, 1995). As a magnetic noise survey had already been undertaken in this area the magnetic noise was well constrained at $16.3 \mathrm{nT}$. All techniques were modelled over the simulated vault across a $15 \mathrm{~m}$ square grid in concrete (parameters in Table 1) and the results are visualised in Figs. 12(a)-(d). The overall detection probabilities calculated were $84 \%$ (magnetic), $57 \%$ (gravity), and over $99 \%$ for gravity gradient and GPR. However, the confines of the site position (approximately $70 \mathrm{~cm}$ across) allowed just one survey line. The probabilities calculated for a single survey line directly over the cavity were $24 \%$ (magnetic), 7.5\% (gravity), 98\% (gravity gradient), and over 99\% (GPR). Hence, both the gravity gradient and GPR techniques were applicable for cavity detection on this site. The choice is then logistical and so GPR was chosen because the technique is much faster in the field.

A PE100A GPR (1000 V) system with $200 \mathrm{MHz}$ antenna was used because the target is shallow. A $15 \mathrm{~m}$ survey in the NW corner of the Middlesex Hospital site was recorded (Fig. 12(e)) with antenna separation of $0.5 \mathrm{~m}, 32$ stacks and $0.1 \mathrm{~m}$ step size (Sensors Software Inc., 2003). Data quality was high so processing was limited to noisy trace deletion, dewow filter, SEC gain, and 2nd power attribute function to highlight strong amplitude reflections typical of cavities. The GPR results show the technique choice was applicable as the strong amplitude reflections of the vaults were clearly detected (Fig. 13(a)). The vaults are seen to be at the same depth as the exposed vaults $(0.8 \mathrm{~m})$ and approximately the same width (the eastern vault is slightly wider $-3.5 \mathrm{~m}$ ). The heights of the vaults are unknown as there is no reflection from the base of the vault and the single survey line means that the lateral extent is unknown. 

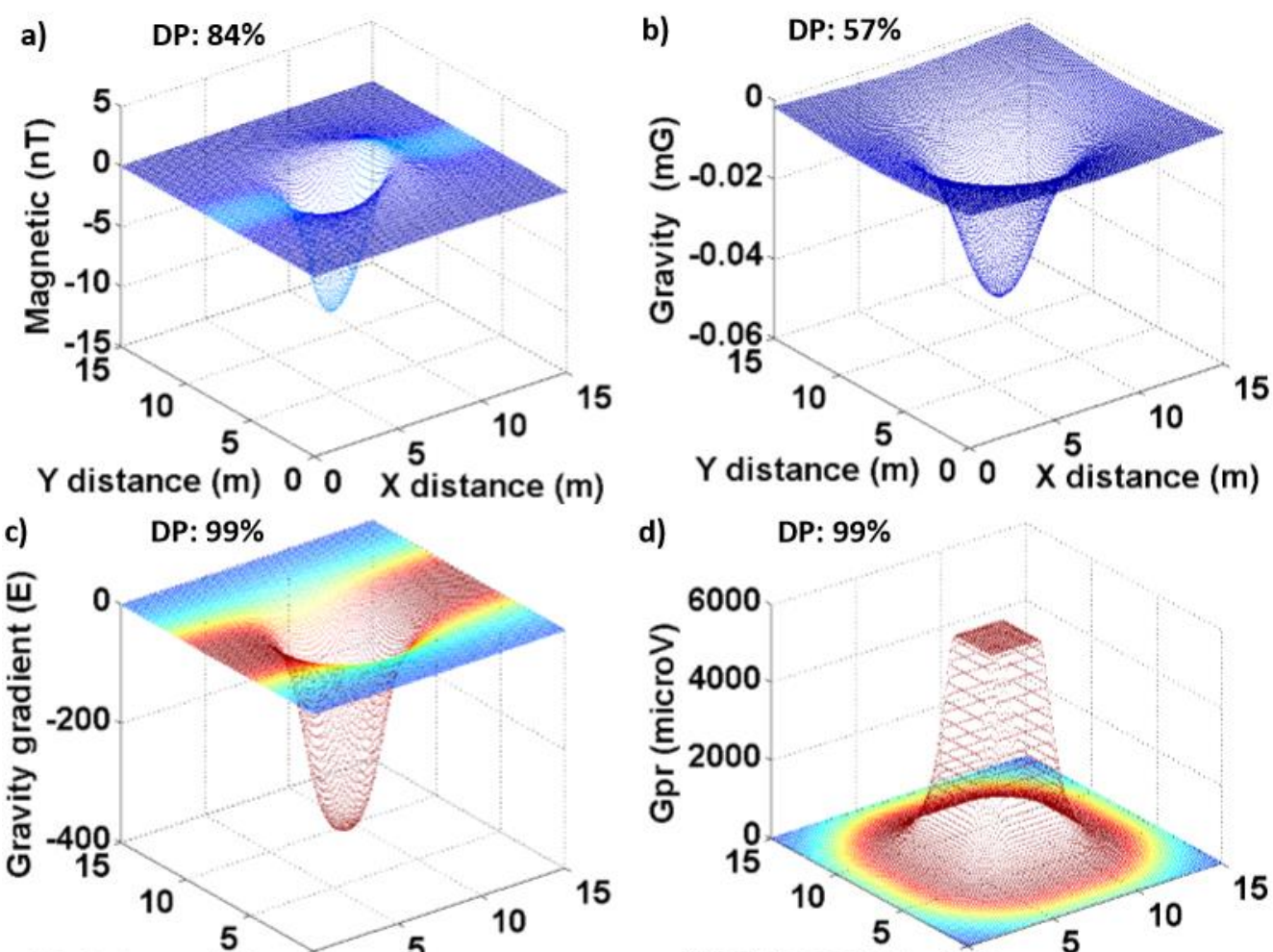

d) DP: $99 \%$

$\mathrm{Y}$ distance $(\mathrm{m}) \quad 0 \quad 0 \quad \mathrm{X}$ distance $(\mathrm{m})$
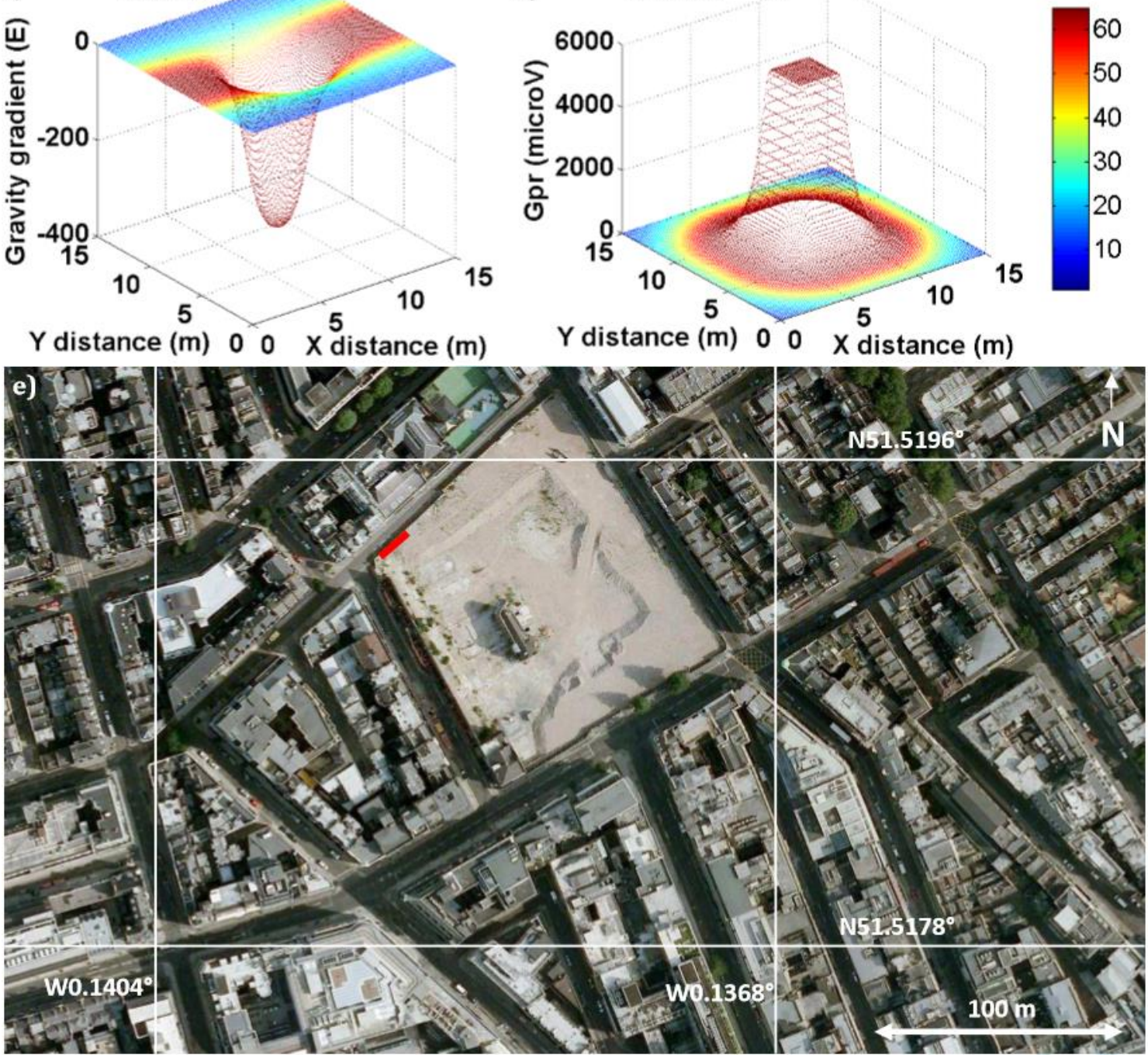

Figure 12. Modelled signal results over the pavement vaults. $D P=$ overall detection probability. a) magnetic, b) gravity, c) gravity gradient and d) GPR. e) Survey location (Google, 2011).

Comparison of the amplitude recorded on individual traces directly over the pavement vaults and the modelled signal amplitude shows more energy reflected from the vaults than was modelled (Fig. 13(b)). The modelled peak voltage directly above the cavity is $5.48 \mathrm{mV}$ and the 
measured amplitude at the site ranged from 2-35 mV over both vaults. Although the widths of the modelled anomalies match the measured anomalies, the amplitude is generally too small. Estimation of the geophysical parameters of the concrete could be a source of error in the modelling. Experimenting with a range of dielectric constants found that Portland Cement $($ dielectric constant $=11($ Carino, 2010) $)$ creates the anomaly closest to that measured in the field (Fig. 13(b)).
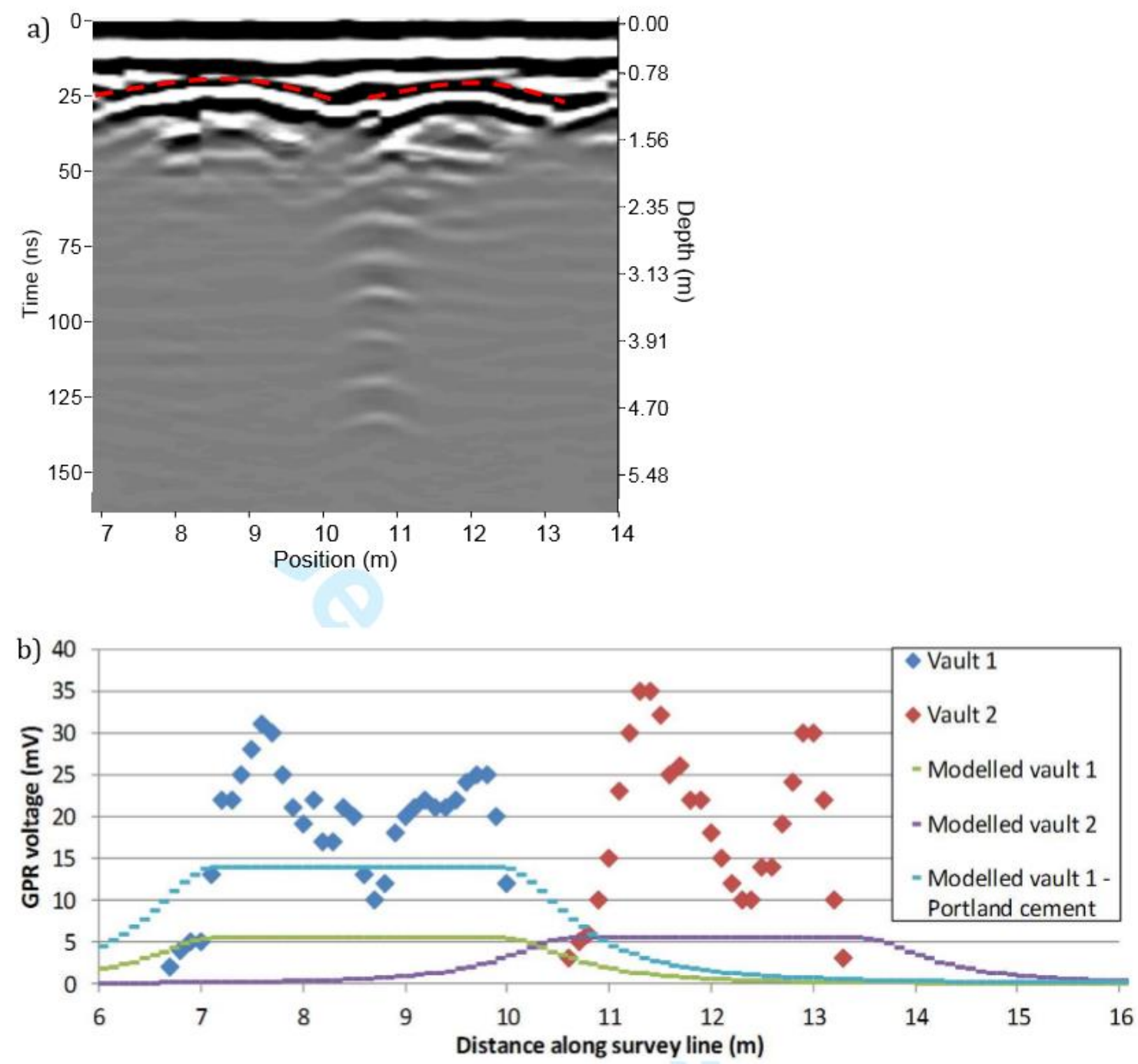

Figure 13. a) Processed section above two pavement vaults (survey location shown in Fig. 12(e)) showing the strong reflection from the vaults (white dashed lines). b) Magnitude of signal above both pavement vaults compared with the modelled results.

\section{West Wycombe Caves}

The modelling technique was used to aid technique choice to detect a manmade cave in West Wycombe. The cave is $1 \mathrm{~m}$ across, $2 \mathrm{~m}$ high and descends from $13.0 \mathrm{~m}$ to $21.5 \mathrm{~m}$ over a $25 \mathrm{~m}$ stretch. The magnetic noise level was well constrained as on-site noise measurements had previously been measured on the site $(0.007 \mathrm{nT})$. The noise levels for other techniques were estimated from previous similar examples in the literature where available, else typical noise values were used (Table 2). The modelled results show the effect of the descending cave with signal amplitude much larger above the shallow end of the cavity than the deeper end (Figs. 14(a)-(d)). The higher detection probability on survey lines above the shallow end of the cave reflects this. 
The modelled results show that all the techniques have a high chance of detection at these noise levels across the $40 \mathrm{~m}$ by $25 \mathrm{~m}$ grid available on the site. At $1 \mathrm{~m}$ spacing magnetic, gravity gradient and GPR all have over $98 \%$ detection probability while gravity only has $84 \%$. Rounding the top of the cavity to better represent the cave-shape (as in Fig. 1) has only a small effect on the overall probability: $2 \%$ decrease for gravity and less than $1 \%$ for the other techniques. As the magnetic, gravity gradient and GPR methods are all applicable to the site, we can choose between them based on logistical reasons. The magnetic method is chosen because it is faster and more portable that the other two techniques. If line spacing is increased to $2 \mathrm{~m}$ the magnetic detection probability drops below this threshold to $88 \%$ and so $1 \mathrm{~m}$ spacing was chosen. Magnetic data was collected every 0.1 s using a Geometrics 858 Caesium Vapour Magnetometer. The survey lines extended beyond the cavity by over two times the cavity depth to record the entire anomaly (here at least $40 \mathrm{~m}$ where possible). A base station recorded diurnal changes every 20 min. Data was processed using MagMap2000 (Geometrics, 2010). Diurnal data was smoothed with spline filters. Data was despiked and destriped to remove the herringbone effect of bidirectional data collection and a regional trend west-east was removed. The processed data is shown in location in Fig. 14(e).

There is an abrupt decrease in the magnetic field over the cave in the eastern section of the survey. Over the deeper part of the cave in the west, the decrease exists but is more subtle. The increase in magnetic field recorded above the cave at the very east of the survey is most likely caused by the presence of a large iron gate in the cave beneath this point.

Though there is a noticeable decrease in the magnetic field over the cave, the decrease is much larger than modelled (over $10 \mathrm{nT}$ compared to $0.001 \mathrm{nT}$ modelled) and does not match the dipolar shape expected. This disparity could be due to a number of factors. The depth of the cave was based upon three digital elevation models that showed large disparity in this region. Therefore, the cave could be shallower than modelled which would give a larger anomaly. The anomaly could have been exaggerated by the "halo effect"- the increase of subsurface cavity anomalies by the detection of the cracked and weakened area around the cavity. However, the anomaly shape recorded does still not match the expected dipolar shape and so it is most likely that the large decrease could be due to a change in geology and not the cavity itself. Removal of this geological trend could reveal the anomaly caused by the cavity allowing a true comparison between the modelled and measured anomaly. However, the orders of magnitude difference between the two anomalies currently is too great for any true comparison. This highlights the importance of consideration of geological changes along the survey line and the consequent obscuration of the subtle cavity signal (see Discussion). For this reason it is often important to conduct more than one type of geophysical survey over a site.

\section{Discussion}

Accuracy of material geophysical parameters is vital in modelling the weak geophysical signature associated with cavities. However, estimates of physical properties of some materials vary by orders of magnitude, and so the associated errors limit the accuracy of modelling. Milsom (2003) lists limestone susceptibility ranging from 10-1,000 SI $\times 10^{6}$. This range varies the modelled signal amplitude and in turn the detection probability. For a $1 \mathrm{~m}$ sided cube air cavity at $3 \mathrm{~m}$ depth in limestone, this susceptibility range translates to magnetic method detection probabilities from $29 \%$ to $98 \%$ at typical noise levels, and from $9 \%$ to $61 \%$ at brownfield noise levels; a range of $69 \%$ and $52 \%$ respectively. The magnetic method has the largest variation in parameter value and so the largest range in detection probability, but this problem also affects other techniques. This is a limitation to this modelling but the integration of on-site parameter measurements (i.e. from initial cores) should constrain the parameters and improve accuracy. 
a) DP: $98 \%$

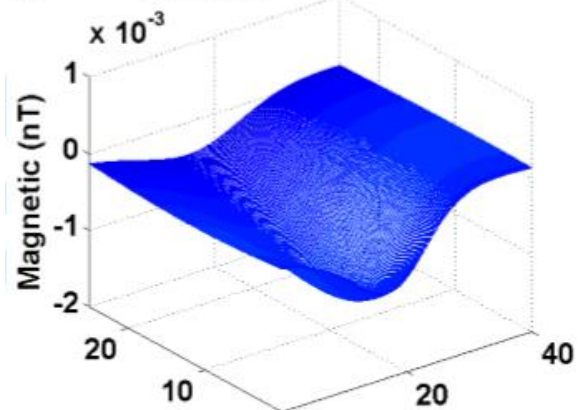

$Y$ distance $(\mathrm{m}) \quad 0 \quad 0 \quad \mathrm{X}$ distance $(\mathrm{m})$ c) DP: $99 \%$

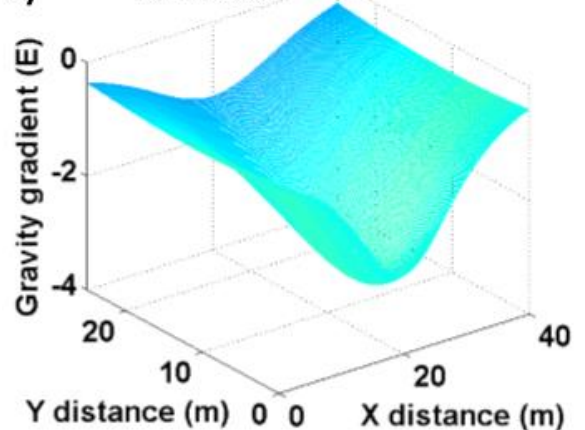

b) DP: $84 \%$

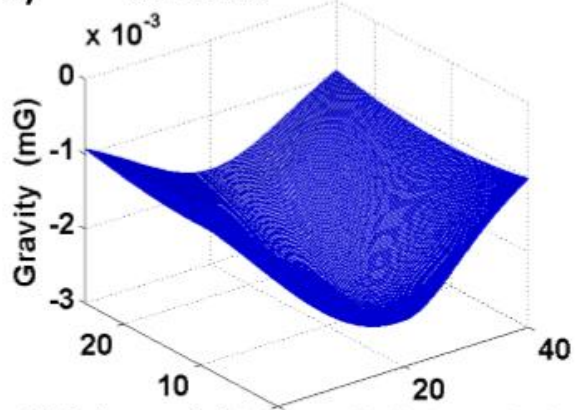

$\mathrm{Y}$ distance $(\mathrm{m}) \quad 0 \quad 0 \quad \mathrm{X}$ distance $(\mathrm{m})$

d) DP: $99 \%$

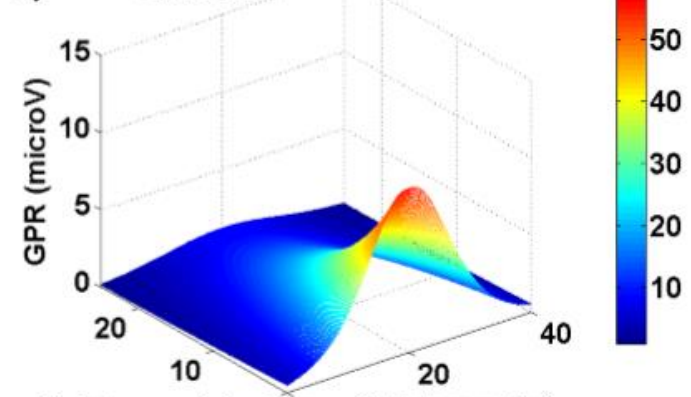

$\begin{array}{lllll}Y & \text { distance }(m) & 0 & 0 & X \text { distance }(m)\end{array}$

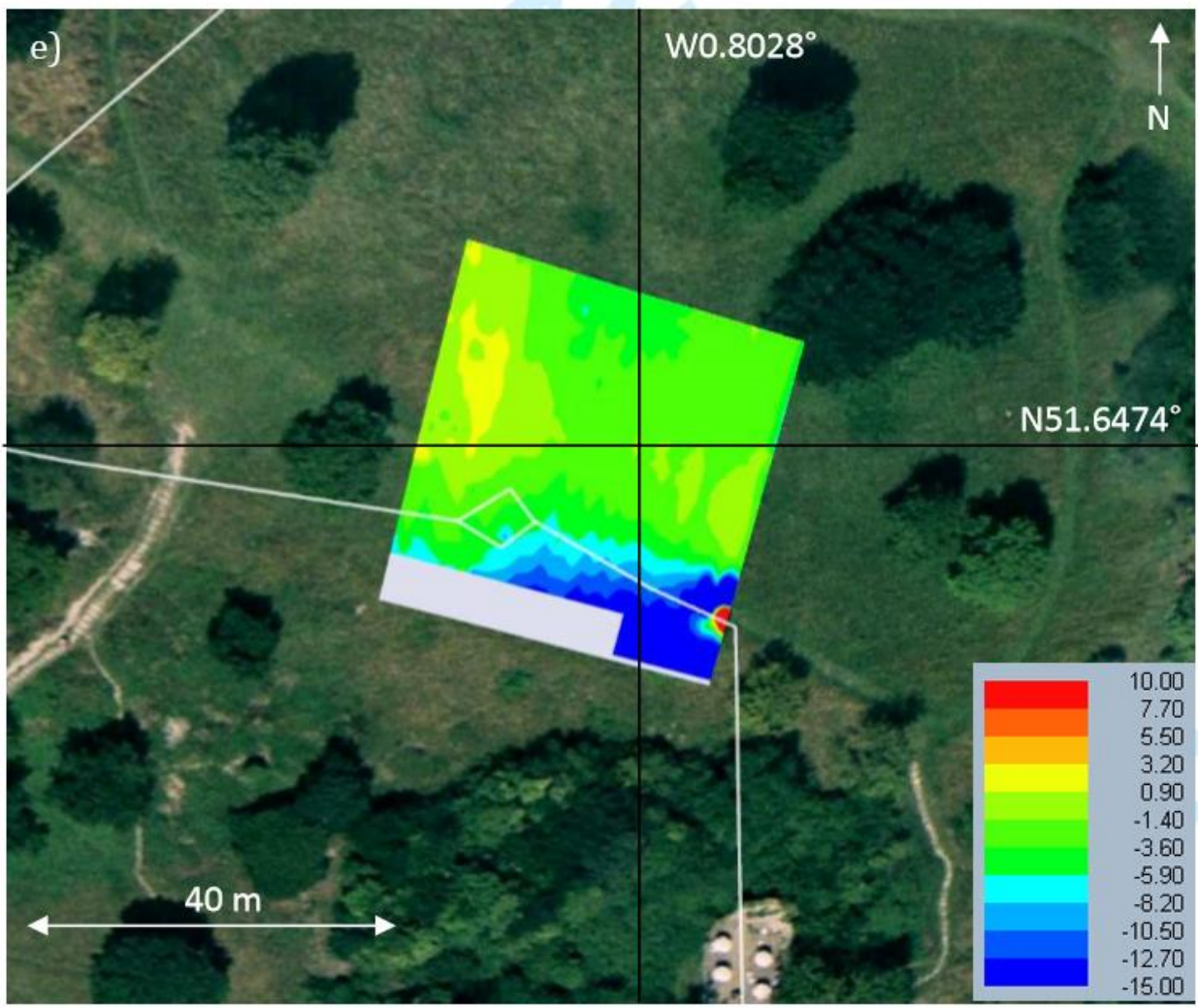

Figure 14. Modelled results above the descending cave for four geophysical techniques: a) magnetic, b) gravity, c) gravity gradient, d) GPR. The colour bar indicates detection probability (\%). DP= overall detection probability. e) Magnetic field measured over the cave. The colour bar indicates magnetic field (nT). The measurements are positioned on a satellite image of the area with a white line representing the surface projection of the cave (Google, 2011). 
This model assumes that signal measured in the field is only a result of the cavity presence and randomly generated noise. However, in reality, other signal will be received from elsewhere in the geological environment. Signal from undulating bedrock and from surface features may obscure a cavity or be mistaken for a cavity in real data. This will also be true of signal from surface objects such as buildings near a site. Comparison of all possible features' amplitude should be assessed in future iterations of this work. Non-uniqueness of geophysical signal can confuse data interpretation and it is often appropriate to use more than one technique; detection probability for multiple techniques should also be explored.

Daniels et al. (1988) state that the radar range equation is not suitable for GPR modelling with depths less than $2 \mathrm{~m}$. However, fairly good results were found when comparing the modelled values with the Middlesex Hospital field measurements. This suggests that the technique could be viable. More research is recommended in comparing existing GPR modelling techniques at a range of depths.

Future study on this work should incorporate further techniques including resistivity and seismic techniques. These techniques will allow the modelling of detection of deeper cavities and a broader comparison. More complicated cavity shapes should be modelled including the 'halo' effect of weakened rock surrounding a cavity and the infill found beneath a migrating cavity. Further case studies should be completed with all techniques for verification and comparison with the modelled results.

\section{Conclusions}

The signal response of the gravity, gravity gradient, magnetic, magnetic gradient and GPR methods is modelled over a range of typical 3D cavity shapes. The overall probability of cavity detection for each individual technique and various survey parameters are calculated, allowing engineers and geophysicists to discriminately choose appropriate geophysical techniques.

Tests on the range of techniques showed that their use was conditional to site characteristics, though gravity gradient and GPR are shown to have high detection probabilities in most near surface environments modelled. Detection probability is shown to be dependent on site specific site parameters such as the geophysical parameters of the cavity and the host material, survey spacing and site noise level. Variation of each subsurface parameter affects the signal intuitively but the complexity of the combination of parameters, especially in 3D, emphasised the need for mathematical modelling of geophysical methods rather than relying on rules of thumb or speculation based on previous field work. Site noise level and survey profile spacing are shown to have the most influence on the minimum detectable cavity size and detection probability, while the host material and data deletion have a less significant effect. Cavity shape and makeup were shown to have a large effect on detection probability, and so the modelling of typical cavity shapes in this study is an important step towards accurate prediction of the feasibility of geophysics on a given site. In the tests conducted, bell pits are shown to have a higher detection probability for the gravity and magnetic methods than other typical cavity shapes. The magnetic technique detection probability is shown to be greatly influenced by the shaft lining material. Modelling results showed that a north-south magnetic survey direction may not always be optimal and is dependent on the subsurface environment.

Modelling technique choice was tested in two case studies. For the first site, the gravity gradient and GPR methods were found to be applicable. The GPR technique was chosen for its speed and successfully detected the vaults, with relatively comparable modelled and measured signals. In the other case the modelling yielded signals much weaker than modelled. The modelled geological structure was possibly too simplified with geophysical changes obscuring 
the cavity anomaly. Further field testing is a future aim of this work along with the expansion of the functionality of the model.

\section{Acknowledgements}

I would like to thank my supervisors Dr. Pedro Ferreira, Prof. Peter Sammonds and Tim Hartlib, for their help and guidance. I thank Ramboll, UCL and EPSRC for this opportunity and the funding provided.

\section{References}

Ali, S.H., 2009, Mining in China: A primary ecological and human health concern: China Environment Series, 10, 97-102.

Anderson, N., and Ismail, A., 2003, A generalized protocol for selecting appropriate geophysical techniques: in Geophysical Technologies for Detecting Underground Coal Mine Voids: An Interactive Forum.

Ballard, R.F., Cuenod, Y., and Jenni, J.P., 1982, Detection of karst cavities by geophysical methods: Bulletin of Engineering Geology and the Environment, 26, 153-157.

Barclay, C., 2010, Greenfield, Brownfield Sites and Planning: in Science and Environment Section, House of Commons Library.

Barnett, C.T., 1976, Theoretical modeling of the magnetic and gravitational fields of an arbitrarily shaped three-dimensional body: Geophysics, 41, 1353-1364.

Breiner, S., 1999, Applications manual for portable magnetometers. Geometrics.

British Geological Society, 2011, Soluble rocks (dissolution): in Geosure: National Ground Stability Data.

British Geological Survey, 2010, Directory of Mines and Quarries Minerals U.K., 9th ed.: NERC.

Butler, D., 2008, Detection and characterization of subsurface cavities, tunnels and abandoned mines: Near-Surface Geophysics and Human Activity, 578-584.

Butler, D.K., 1984, Microgravimetric and gravity gradient techniques for detection of subsurface cavities: Geophysics, 49(7), 1084-1096.

Cai, J., and McMechan, G.A., 1995, Ray-based synthesis of bistatic ground-penetrating radar profiles: Geophysics, 60, 87-96.

Cardarelli, E., Cercato, M., Cerreto, A., and Di Filippo, G., 2009, Electrical resistivity and seismic refraction tomography to detect buried cavities: Geophysical Prospecting, 00, 1-11.

Chamon, N., and Dobereiner, L., 1988, An example of the use of geophysical methods for the investigation of a cavern in sandstones: Bulletin of Engineering Geology and the Environment, 38, 37-43.

Carino, N.J., 2010, Nondestructive test methods: in Concrete Construction Engineering Handbook, CRC Press, 21-1.

Daniels, D.J., 2004, Ground penetrating radar, 2nd ed.: Institution of Electrical Engineers.

Daniels, D.J., Gunton, D.J., and Scott, H.F., 1988, Introduction to subsurface radar: in IEE Proceedings, 135, Part F(4), 278-320.

David, A., 2008, Geophysical survey in archaeological field evaluation: in English Heritage Research and Professional Services Guideline.

EAGE Conference and Exhibition workshop discussion, 2012, Integrated Geosciences for Subsurface Instabilities, Offshore and Onshore. EAGE Copenhagen, 3rd June.

Edmonds, C.N., 2008, Karst and mining geohazards with particular reference to the Chalk outcrop, England: Quarterly Journal of Engineering Geology and Hydrogeology, 41, 261278.

Elawadi, E., El-Qady, G., and Salem, A., 2001, Detection of Cavities Using Pole-Dipole Resistivity Technique: Memoirs of the Faculty of Engineering, Kyushu University, 61(4). 
Erkan, K., and Jekeli, C., 2011, A comparative analysis of geophysical fields for multi-sensor applications: Journal of Applied Geophysics, 74(1-2), 142-150.

Fajklewicz, Z., Glinski, A., and Sliz, J., 1982, Some applications vertical gradient of the underground tower gravity: Geophysics, 47, 1688-1692.

Fehdi, C., Baali, F., Boubaya, D., and Rouabhia, A., 2010, Detection of sinkholes using 2D electrical resistivity imaging in the Cheria Basin (north-east of Algeria): Arabian Journal of Geosciences, 4(1-2), 181-187.

Filahi, M., Andrieux, P., Tabbagh, A., Rejiba, F., Najine, A., Jaffal, M., Casas, A., and Angelova, D., 2008, Detection and mapping of the underground cavities by geophysical methods: ground penetrating radar, seismic waves and electrical imagery - case of BéniMellal city (Morocco): Geophysical Research Abstracts, 10, 8657-8657.

Geometrics, 2010, MagMap2000 software.

Geoscan Research, 2012, FM256 Data Quality - Processing and Analysis with Geoplot: Geoscan Research

Google, 2011, Google Earth (6.1.0.5001).

Guptasarma, D., and Singh, B., 1999, New scheme for computing the magnetic field resulting from a uniformly magnetized arbitrary polyhedron: Geophysics, 64(1), 70-74.

Healy, P.R., and Head, J.M., 1984, Construction over abandoned mine workings: International Journal of Rock Mechanics and Mining Sciences, 21, 146-146.

Kendorski, F.S., 2004, Problems in "void" detection in coal mine water hazards: in 23rd International Conference on Ground Control in Mining.

Khesin, B.E., Alexeyev, V.V., and Eppelbaum, L.V., 1996, Interpretation of geophysical fields in complicated environments, Springer.

Kosmatka, S.H., 2010, Properties and Performance of Normal-Strength and High-Strength Concrete: in Concrete Construction Engineering Handbook, 5-16.

Laswell, S., Engel, R., Cassidy, J., Courtier, N., and Henton, J., 2008, Recent observations of increased seismic background noise using gPhone gravity meters, Micro-g LaCoste documentation.

Littlejohn, G.S., 1979, Surface stability in areas underlain by old coal workings: Ground Engineering, 12, 222-230.

Manzanilla, L., Barba, L., Chávez, R., Tejero, A., Cifuentes, G., and Peralta, N., 1994, Caves and Geophysics: an Approximation To the Underworld of Teotihuacan: Mexico. Archaeometry, 36, 141-157.

Martinez, A., Beaty, D.S., Feldman, H.R., and Kruger, J.M., 1996, Fluvial Sandstone Reservoir, Northeast Kansas, High-Resolution Ground-Penetrating Radar: Kansas Geological Survey, Open-file Report.

McCann, D.M., Jackson, P.D., and Culshaw, M.G., 1987, The use of geophysical surveying methods in the detection of natural cavities and mineshafts: Quarterly Journal of Engineering Geology and Hydrogeology, 20, 59-73.

McEnroe, S.A., 1998, Magnetic susceptibility measurements on concrete samples: Geological Survey of Norway Report.

Miller, R., and Steeples, D., 1991, Detecting voids in a $0.6 \mathrm{~m}$ coal seam, $7 \mathrm{~m}$ deep, using seismic reflection: Geoexploration, 28, 109-119.

Milsom, J., 2003, Field Geophysics (Geological Field Guide), 3rd ed.: John Wiley and Sons Ltd.

Milsom, J.J., and Eriksen, A., 2011, Field Geophysics (Geological Field Guide), 4th ed.: WileyBlackwell.

Mochales, T., Pueyo, E.L., Casas, A.M., and Soriano, M.A., 2007, Magnetic prospection as an efficient tool for doline detection: a case study in the central Ebro Basin (northern Spain): Geological Society, London, Special Publications, 279, 73-84.

Nikitin, A.A., and Tarchov, A.G., 1973, Estimation of the likelihood of the detection of geophysical anomalies: Rarwied. Gieofiz., 59, 56-62. 
Ove Arup and Partners, 1976, Reclamation of Derelict Land: Procedure for Locating Abandoned Mine Shafts: Planning, Regional and Minerals Directorate, Department of the Environment.

Parasnis, D.S., 1996, Principles of Applied Geophysics, Springer.

Pueyo-Anchuela, Ó., Casas-Sainz, A.M., Soriano, M. A., and Pocoví-Juan, A., 2010, A geophysical survey routine for the detection of doline areas in the surroundings of Zaragoza (NE Spain): Engineering Geology, 114(3-4), 382-396.

Pánisová, J., and Pašteka, R., 2009, The use of microgravity technique in archaeology: A case study from the St. Nicolas Church in Pukanec, Slovakia: Contributions to Geophysics and Geodesy, 39, 237-254.

Raybould, D.R., and Price, D.G., 1966, The use of the proton magnetometer in engineering geological investigations: in Proceedings First Congress International Society of Rock Mechanics, Lisbon, 11-14.

Reynolds, J.M., 1997, An Introduction to Applied and Environmental Geophysics: WileyBlackwell.

Roberts, R.L., 1997, Modeling near-field GPR in three dimensions using the FDTD method: Geophysics, 62(4), 1114-1126.

Rodriguez Castillo, R., and Reyes Gutierrez, R., 1992, Resistivity identification of shallow mining cavities in Real del Monte, Mexico: Engineering Geology, 33, 141-149.

Roe, M., 2008, The Bell Pit: Lead Mining In the Yorkshire Dales.

Roth, M., Mackeya, J.R., Mackeya, C., and Nyquist, J.E., 2002, A case study of the reliability of multielectrode earth resistivity testing for geotechnical investigations in karst terrains: Engineering Geology, 65, 225-232.

Rybakov, M., Goldshmidt, V., Fleischer, L., and Rotstein, Y., 2001, Cave detection and 4-D monitoring: A microgravity case history near the Dead Sea: The Leading Edge, 20, 896900.

Rybakov, M., Rotstein, Y., Shirman, B., and Al-Zoubi, A., 2005, Cave detection near the Dead Sea - a micromagnetic feasibility study: The Leading Edge, 24, 585-590.

Salem, A., Lei, K., Green, C., Fairhead, J.D., and Stanley, G., 2010, Removal of cultural noise from high-resolution aeromagnetic data using a two stage equivalent source approach: Exploration Geophysics, 41, 163-169.

Saribudak, M., 2001, Urban Geophysics: A Mapping Of Mount Bonnell Fault And Its Karstic Features In Austin, Texas: Environmental Geophysics Associates.

Scollar, I., Tabbagh, A., Hesse, A., and Herzog, I., 2009, Archaeological Prospecting and Remote Sensing: Cambridge University Press.

Seigel, H., 1995, A guide to high precision land gravimeter surveys: Scintrex LTD, Concord, Ontario.

Sensors Software Inc., 2003, EKKO_View Enhanced and EKKO_View Deluxe User's Guide: Sensors Software Inc.

Sharma, P. V., 1997, Environmental and Engineering Geophysics: Cambridge University Press.

Singh, B., and Guptasarma, D., 2001, New method for fast computation of gravity and magnetic anomalies from arbitrary polyhedral: Geophysics, 66(2), 521-526.

Styles, P., 2003, Feature Environmental geophysics: a site characterization tool for urban regeneration in the post-mining era: Geology Today, 19, 173-178.

Styles, P., Toon, S., Thomas, E., and Skittrall, M., 2006, Microgravity as a tool for the detection, characterization and prediction of geohazard posed by abandoned mining cavities: First Break, 24, 51-60.

Talwani, M., 1965, Computation with the help of a digital computer of magnetic anomalies caused by bodies of arbitrary shape: Geophysics, 30, 797-817.

Talwani, M., and Ewing, M., 1960, Rapid computation of gravitational attraction of 3D bodies of arbitrary shape: Geophysics, 25, 203-225. 
Tuckwell, G., Grossey, T., Owen, S., and Stearns, P., 2008, The use of microgravity to detect small distributed voids and low-density ground: Quarterly Journal of Engineering Geology and Hydrogeology, 41, 371-380.

U.S. Army Corps of Engineers, 1995, Geophysical exploration for engineering and environmental investigations: Engineer manual.

Uduwawala, D., and Norgren, M., 2004, A complete FDTD simulation of a real GPR antenna system operating above lossy and dispersive grounds: Progress In Electromagnetics Research, 50, 209-229.

Xia, J., Nyquist, J., Xu, Y., Roth, M., and Miller, R., 2007, Feasibility of detecting near-surface feature with Rayleigh-wave diffraction: Journal of Applied Geophysics, 62, 244-253. 